\title{
NEUROPSYCHOPHARMACOLOGY REVIEWS Sex differences in the developing brain: insights from multimodal neuroimaging
}

\author{
Antonia N. Kaczkurkin ${ }^{1}$, Armin Raznahan ${ }^{2}$ and Theodore D. Satterthwaite ${ }^{1}$
}

Youth (including both childhood and adolescence) is a period when the brain undergoes dramatic remodeling and is also a time when neuropsychiatric conditions often emerge. Many of these illnesses have substantial sex differences in prevalence, suggesting that sex differences in brain development may underlie differential risk for psychiatric symptoms between males and females. Substantial evidence documents sex differences in brain structure and function in adults, and accumulating data suggests that these sex differences may be present or emerge during development. Here we review the evidence for sex differences in brain structure, white matter organization, and perfusion during development. We then use these normative differences as a framework to understand sex differences in brain development associated with psychopathology. In particular, we focus on sex differences in the brain as they relate to anxiety, depression, psychosis, and attention-deficit/hyperactivity symptoms. Finally, we highlight existing limitations, gaps in knowledge, and fertile avenues for future research.

Neuropsychopharmacology (2019) 44:71-85; https://doi.org/10.1038/s41386-018-0111-z

\section{INTRODUCTION}

Youth (including both childhood and adolescence) is a period when the brain undergoes dramatic remodeling. Adolescence is further marked by hormonally induced changes in both the body and the brain [1-4]. During this period of remodeling and growth, psychiatric symptoms frequently emerge, leading many neuropsychiatric disorders to be re-conceptualized as disorders of brain development. Notably, many of the disorders which begin during childhood and adolescence have prominent sex differences in their prevalence [5-10]. For example, mood and anxiety disorders are almost twice as common in females $[6,7,11]$, while attention deficit/hyperactivity disorder is 2.4 times more common in males [12].

Such striking epidemiological disparities in psychiatric disorder prevalence have prompted efforts to understand how sex differences in brain development may confer differential risk or resilience for specific symptom domains. Extensive research has established the presence of sex differences in brain structure and function in adults [13], and accumulating evidence is now available regarding the developmental evolution of such sex differences during development $[14,15]$. Such normative data is a critical prerequisite for understanding abnormalities associated with different types of psychopathology.

The purpose of the current review is two-fold. First, we review the evidence for normative sex differences in brain development in youth. In particular, we describe how the development of brain structure (as measured using T1-weighted magnetic resonance imaging), white matter organization (as measured by diffusion imaging), and cerebral blood flow (measured using arterial spinlabeled MRI) differ between males and females during development. Second, we use these normative sex differences as a framework to understand differences between males and females in psychopathology. In particular, we focus on sex differences in the brain as they relate to types of psychopathology with prominent sex differences in their burden in the population, including anxiety, depression, psychosis, and attention-deficit/ hyperactivity symptoms. Of note, in this review we focus on statistically significant sex differences between males and females. Finally, we highlight existing limitations, gaps in knowledge, and fertile avenues for future research.

\section{SEX DIFFERENCES IN BRAIN STRUCTURE: T1-WEIGTHED IMAGING \\ Total brain volume}

Total brain volume provides a global index that shows striking changes during development. In humans, the third trimester of pregnancy represents a time of rapid growth, with total brain volume increasing approximately 5 -fold in size [16]. During this time, there is accelerated neuron production, migration, and differentiation, as well as the formation of gyri and sulci $[16,17]$. Changes in the size and organization of the brain continue after birth and by the age of 2 years, a child's brain is about $80 \%$ of the size of the adult brain [18]. Although the size of the brain increases dramatically following birth, there is much less change in total brain size thereafter [17].

The most consistent sex difference reported in terms of total brain volume is the finding of larger overall brain sizes in males compared to females, which is apparent across development and into adulthood. Brain sizes are about 9-12\% larger in male children [15, 19-21], adolescents [15, 19-22], and adults [14, 15, $21,23,24]$. In terms of longitudinal trajectories, there is some evidence that females reach their peak value of brain volume earlier than males $[25,26]$. However, some cross-sectional work

\footnotetext{
${ }^{1}$ Department of Psychiatry, Perelman School of Medicine, University of Pennsylvania, Philadelphia, PA 19104, USA and ${ }^{2}$ Developmental Neurogenomics Unit, National Institute of Mental Health, Bethesda, MD 20814, USA

Correspondence: Theodore D. Satterthwaite (sattertt@pennmedicine.upenn.edu)
}

Received: 14 March 2018 Revised: 21 May 2018 Accepted: 23 May 2018

Published online: 6 June 2018 

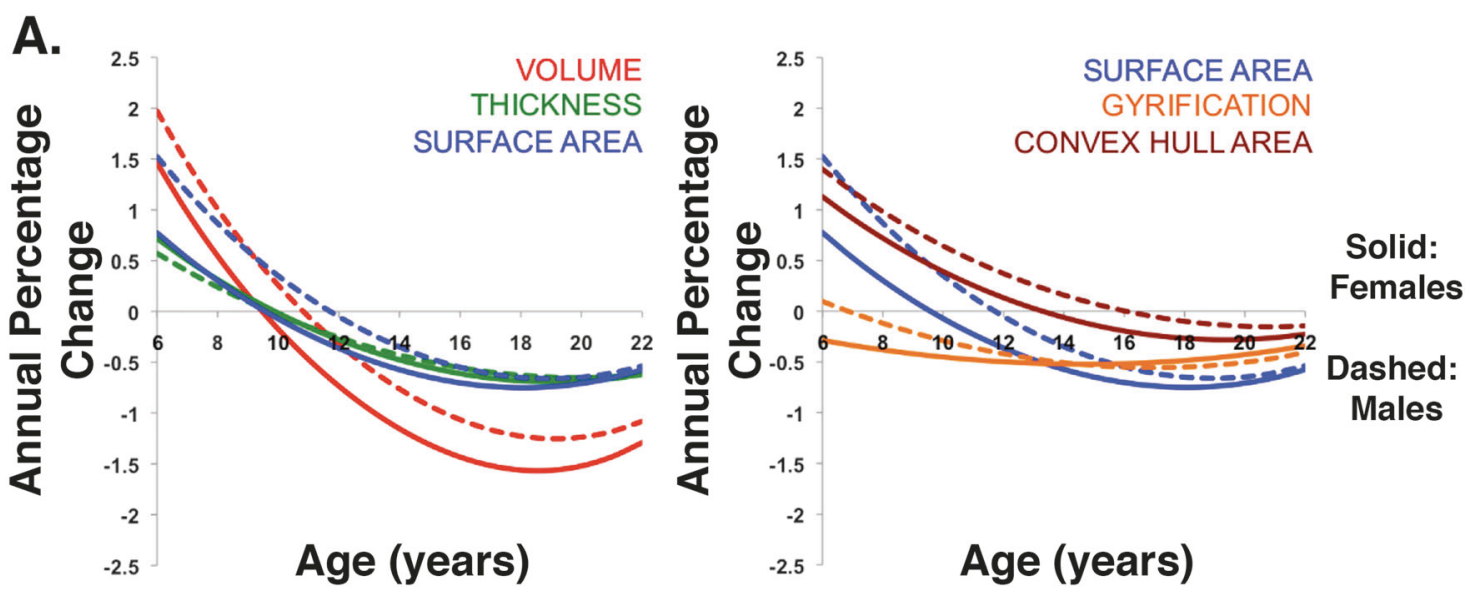

B.

GMV

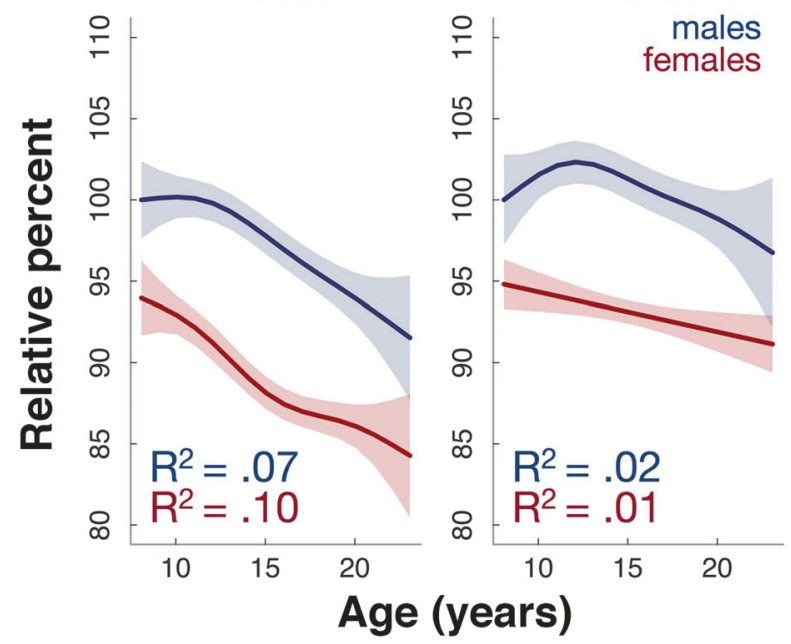

C.

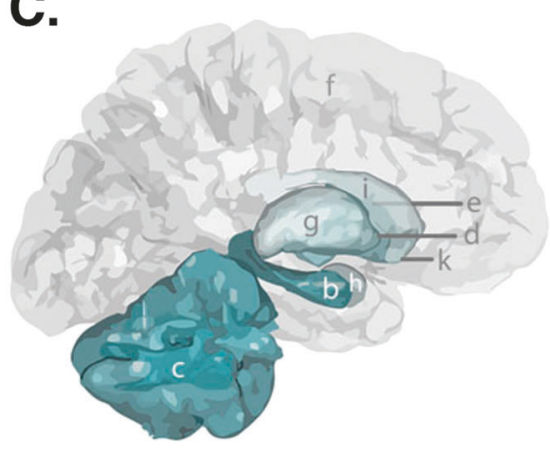

a. Cerebral white matter

b. Hippocampus

c. Cerebellar cortex

d. Pallidum

e. Putamen

f. Cerebral cortex

g. Thalamus

h. Amygdala

i. Caudate

j. Cerebellar white matter

k. Accumbens
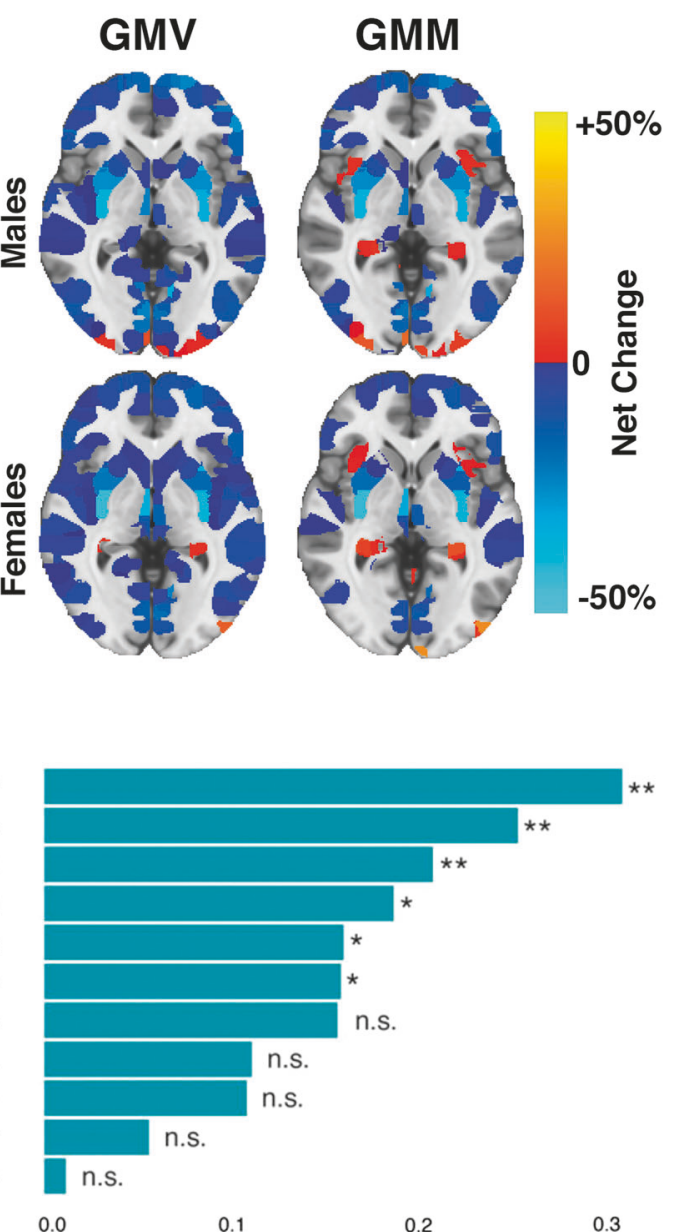

$\log ($ variance ratio)

Fig. 1 Female youth generally show smaller volumes than male youth (uncorrected for total brain size) while males show greater variability in brain volumes than females. a Sex differences in cortical volumes depend on the complex interaction between cortical thickness, convex hull area, and gyrification (adapted with permission from ref. [27]). b Male youth show greater gray matter volume (GMV) and gray matter mass $(G M M)$ than female youth, where $G M M=G M V \times G M D$. Brain maps indicate the percentage net change explained by sex (adapted with permission from ref. [21]). c Males show greater brain volume variance than females across multiple structures (adapted with permission from ref. [48])

finds that the difference between males and females in terms of total brain volume is relatively consistent across the age range [20]. Leveraging over 1250 longitudinally acquired brain scans from 647 healthy individuals aged 3 to 30 years, Raznahan and colleagues showed that differences in cortical volumes depend on the complex interaction between cortical thickness, convex hull area (the area of exposed cortical surface), and gyrification or the folding of the brain's surface [27] (Fig. 1a). In a cross-sectional sample of 1189 youth ages 8 to 23 years, Gennatas and colleagues further showed that not only is total gray matter volume larger in males than females across development, but that estimated gray matter mass is also greater in males [21] (Fig. 1b). 
Cerebral gray matter and white matter volume

Beyond total brain size, brain volume can be divided into cerebral gray and white matter using segmentation techniques. Gray matter consists of neuronal cell bodies, glial cells, dendrites, unmylenated axons, and synapses, but relatively few myelinated axons. In contrast, white matter consists of relatively few cell bodies and many myelinated axons, giving rise to white matter's lighter appearance. Brain development from the fetal period through childhood, adolescence, and young adulthood is characterized by increased myelination and simultaneous pruning of synapses and axons [17]. Thus, in general, cerebral gray matter volumes increase with increasing brain volumes in early childhood, followed by a decrease during later development, while cerebral white matter volume tends to increase consistently over development [19-21, 28]. However, it remains unclear whether these reductions in gray matter are due to maturational processes related to pruning or intracortical myelination [29]. Longitudinal studies reveal a nonlinear pattern of gray matter volume development during youth, with pre-adolescent increases in cortical gray matter volume followed by postadolescent decreases $[25,30]$. In contrast, cerebral white matter volume shows a relatively linear increase from childhood to young adulthood in both longitudinal and cross-sectional studies $[19,25,31]$.

Consistent with males having larger total brain volumes, uncorrected white and gray matter volumes are also larger in males [23]. Conversely, females have been reported to have a greater ratio of gray matter to white matter than males $[23,32-34]$. However, these studies relied on relatively small samples. Other studies place less emphasis on gray-white matter ratios and instead focus on sex differences in developmental trends. Males show greater age-related decreases in gray matter volume compared to females in cross-sectional studies [19]. Sex differences are also apparent in cerebral white matter volumes. Compared to females, cross-sectional research reveals that males show evidence of greater white matter volumes in the corpus callosum in adolescence [19].

\section{Regional differences in brain volume}

Structural maturation of the brain proceeds in a coordinated regional pattern across development. In terms of gray matter loss, phylogenetically newer higher-order association areas such as the frontal lobe mature only after lower-order sensorimotor regions $[20,30]$. Similarly, longitudinal studies demonstrate a rostro-caudal pattern of growth in white matter regions, such as the corpus callosum [31]. Sex differences in the age-related trajectories of regional volumes have been reported, with males showing linear changes in volume and females showing more curvilinear patterns in cross sectional samples [20]. Furthermore, subcortical regions show marked hemispheric effects during development, with males and females showing different longitudinal trajectories of change [35].

Regional sex differences are most commonly reported in medial temporal lobe structures including the hippocampus and amygdala [14]. However, the evidence for sex differences in the hippocampus and amygdala has been mixed, with some studies reporting larger volumes in these regions in females [36-38], others reporting larger volumes in males [22, 39-42], and still others showing no differences or attenuated differences between males and females after controlling for total brain volume [24, 43]. Two meta-analyses that encompass the lifespan demonstrated that uncorrected hippocampal and amygdala volumes were larger in males, but when controlling for total brain volume or intracranial volume, no reliable sex differences were found $[44,45]$.

Despite the mitigation of sex differences in regional volumes after correcting for brain size, a number of large studies that control for total brain volume or intracranial volume have reported sex differences in hippocampal and amygdala volumes. In a large cross-sectional sample of 524 pre-pubertal and post-pubertal youth ages 10 to 22 years, pre-pubertal males and females had similar hippocampal volumes, whereas post-pubertal females showed larger hippocampal volumes than males after controlling for intracranial volume [46]. Notably, this effect was not apparent in the amygdala in this study. Conversely, another cross-sectional study showed that after controlling for intracranial volume in a sample of over 400 typically developing youth ages 8-30, males showed larger volumes in the amygdala compared to females [47]. Likewise, in a large cross-sectional sample of over 1000 youth, 3 to 21 years of age, Wierenga and colleagues showed that the hippocampus and amygdala were significantly larger in males than females even after controlling for intracranial volume [48]. Using a longitudinal sample of 711 neuroimaging scans from 275 youth aged 7-20 years, Goddings and colleagues found that males and females showed similar overall volume change in the amygdala with age but different growth trajectories. Amygdala volumes increased rapidly in females in early puberty before peaking and decreasing, while males showed increasing amygdala volumes throughout puberty [3]. Taken together, sex differences in medial temporal lobe volumes in youth may depend on age and stage of pubertal development.

In contrast, there is consistent evidence documenting sex differences in structural variability. For example, using a longitudinal design, Wierenga and colleagues found that males showed significantly greater variance than females in the hippocampus, pallidum, and putamen, above and beyond differences in mean volumes, and these differences in variance were stable across the developmental age range [48] (Fig. 1c). Higher variance in males compared to females in the hippocampus, nucleus accumbens, amygdala, caudate, pallidum, putamen, and thalamus was also documented in the largest cross-sectional sample to date from the UK Biobank, which included over 5000 adults [24]. These differences in variance remained even after controlling for total brain volume or height [24]. Higher variability in brain volumes in males compared to females may make charting developmental trajectories in male youth more difficult.

\section{Gray matter density}

In contrast to gray matter volume, gray matter density is distinct in that it is a unitless measure related to T1 signal intensity. Gray matter density maps are created by assigning voxels a value of 0 to 1 indicating the relative amount of gray matter in a particular voxel. This "soft segmentation" allows for a measure of the relative density of gray matter in a region, which is in contrast to a hard segmentation where each voxel is assigned to a single tissue type ("gray," "white," or "CSF"). During normative development, gray matter density has been shown to increase over the developmental period [21].

Sex differences in terms of gray matter density are just beginning to be understood. Adult females have greater gray matter density than males across the cortex $[23,49]$. In a large cross-sectional sample of youth ages 8 to 23 years, females showed higher mean gray matter density than males throughout the brain [21] (Fig. 2a). Specifically, Gennatas and colleagues found that sex differences vary with age, with males and females showing no differences in gray matter density at 8 years of age. Females then began to show greater gray matter density across both cortical and subcortical regions soon thereafter [21] (Fig. 2b). Thus, it appears that while females have smaller gray matter volumes than males, the density of these structures is higher. Longitudinal studies are needed to map sex differences in the developmental trajectories of gray matter density and to determine whether changes in volume precede and predict changes in density. 
A.
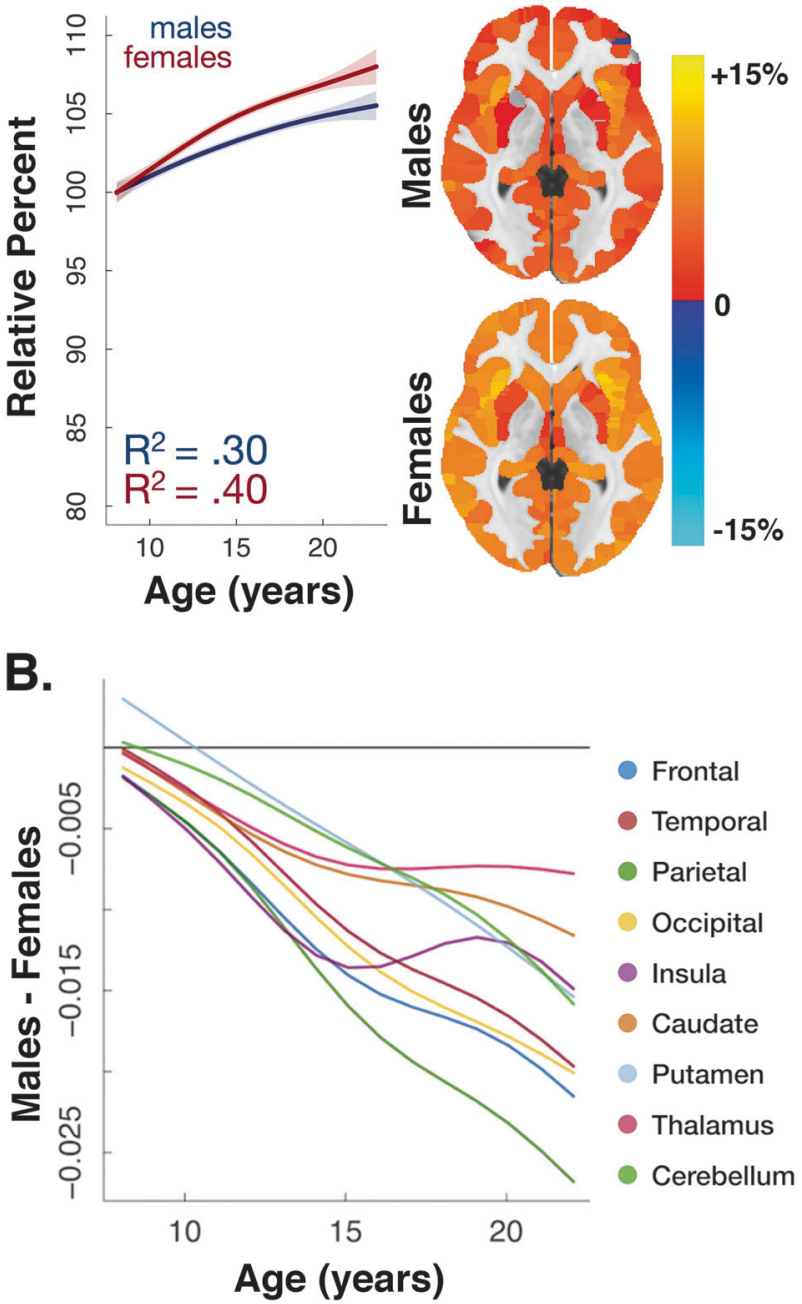

Fig. 2 Developmental sex differences in gray matter density. a Although gray matter density is similar at age 8 in males and females, gray matter density increases more rapidly in females than males throughout adolescence. This differential rate of development results in females having higher gray matter density across the entire brain. b Sex differences vary with age, with males and females showing no differences at 8 years of age. Females then began to show greater gray matter density across many regions soon thereafter. All data adapted with permission from ref. [21]

\section{Cortical thickness}

Cortical volume is the product of cortical thickness and surface area. Cortical thickness refers to the combined thickness of the layers of the cerebral cortex in the human brain, while cortical surface area is a measure of the total area that the surface of the cortex occupies. Cortical thickness is generally a measure of the local or average distance between the white matter surface and the pial surface. The cerebral cortex in humans is comprised of a sheet of neurons with many folds (gyri and sulci) that vary in thickness between 1 and $4.5 \mathrm{~mm}$, with a total average cortical thickness of around $2.5 \mathrm{~mm}$ [50].

Cortical thickening begins around 10-15 weeks of fetal development and increases exponentially during the third trimester [51]. Although the specific trajectory of cortical thickness development is still debated, cortical thickness declines fairly dramatically during development $[21,52]$ (Fig. 3a). Some studies report cubic trajectories in cortical thickness across development. For example, using a longitudinal study, Shaw and colleagues showed that the lateral frontal, lateral temporal, parietal, and occipital cortices were characterized by an initial increase in cortical thickness in childhood, a decline in adolescence, and then a stabilization phase in adulthood [53]. Other longitudinal studies report a curvilinear or inverted u-shape, with cortical thickness increasing in childhood, peaking in late childhood/early adolescence, and then declining later [27]. Mutlu and colleagues found evidence of constant, linear, quadratic, and cubic patterns of cortical thickness development, depending on the brain region examined in their longitudinal study [54]. Conversely, others do not find increases in cortical thickness in childhood and instead find evidence of primarily cortical thinning during this period [47, 55-57] or they find longitudinal increases in cortical thickness restricted to specific regions and more widespread cortical thinning elsewhere [58]. Such mixed evidence may be in part explained by interactions between the development of cortical thickness and sulcal topology. Specifically, in a large crosssectional sample of 932 youth, Vandekar and colleagues found that thicker sulcal cortex displayed linear thinning, whereas thinner gyral cortex displayed nonlinear patterns which included thickening prior to age 14 [59].

Differences between males and females in terms of cortical thickness have been reported. In a cross-sectional sample of over 5000 adults from the UK Biobank, females showed greater cortical thickness across most regions in the brain [24]. Age-related changes in cortical thickness within structural covariance networks also vary substantially between males and females. For example, males display thicker parietal cortices at younger ages, but nearly equivalent cortices by adulthood in cross-sectional samples [60] (Fig. 3b). Using a cross-sectional sample from 7 to 87 years of age, Sowell and colleagues showed that females demonstrated thicker cortices in the right inferior parietal and posterior temporal areas compared to males, even after matching participants on age and total brain volume and after controlling for body size [15] (Fig. 3c). However, the age at which peak levels of global cortical thickness are attained does not appear to differ between males and females [27]. Likewise, no sex differences were found in the trajectory of cortical thickness development with increasing age when examining lobes or the entire brain [27, 47]. Nonetheless, there is evidence that sex differences in regional cortical thickness may depend on age. In a cross-sectional sample of 6-10 year olds, older female youth showed greater cortical thickness than older males in the right insula and sensory areas [61]. Likewise, another cross-sectional developmental study revealed that male youth have greater cortical thickness in the insula, frontal lobe, and occipital lobe than females until adolescence, when this pattern reverses [21]. Thus, there is some evidence that cortical thickness may differ between females than males, but the direction of this effect depends on both age and the region examined.

\section{Cortical surface area and gyrification}

Cortical surface area is distinct from cortical thickness, with only negligible genetic correlations between these two measures and high variability in phenotypic correlations [62-64]. Despite this, surface area undergoes a similar trajectory as cortical thickness during development, with surface area decreasing with increasing age. Specifically, a longitudinal study revealed an inverted ushaped trajectory of cortical surface area maturation, similar to cortical thickness, but the authors noted that surface area peaked later than cortical thickness [27]. Related to cortical surface area is gyrification, or the elaboration of the folded surface of the brain. Gyrification increases rapidly during the third trimester of fetal development allowing for substantial expansion of the cortical surface within the confines of the skull [51]. Throughout childhood and adolescence, there is evidence of a gradual decrease in brain surface complexity measured using gyrification indices [65].

Sex differences are documented in cortical surface area and gyrification. In general, males show greater cortical surface area than females, even after controlling for total brain volume [24]; 

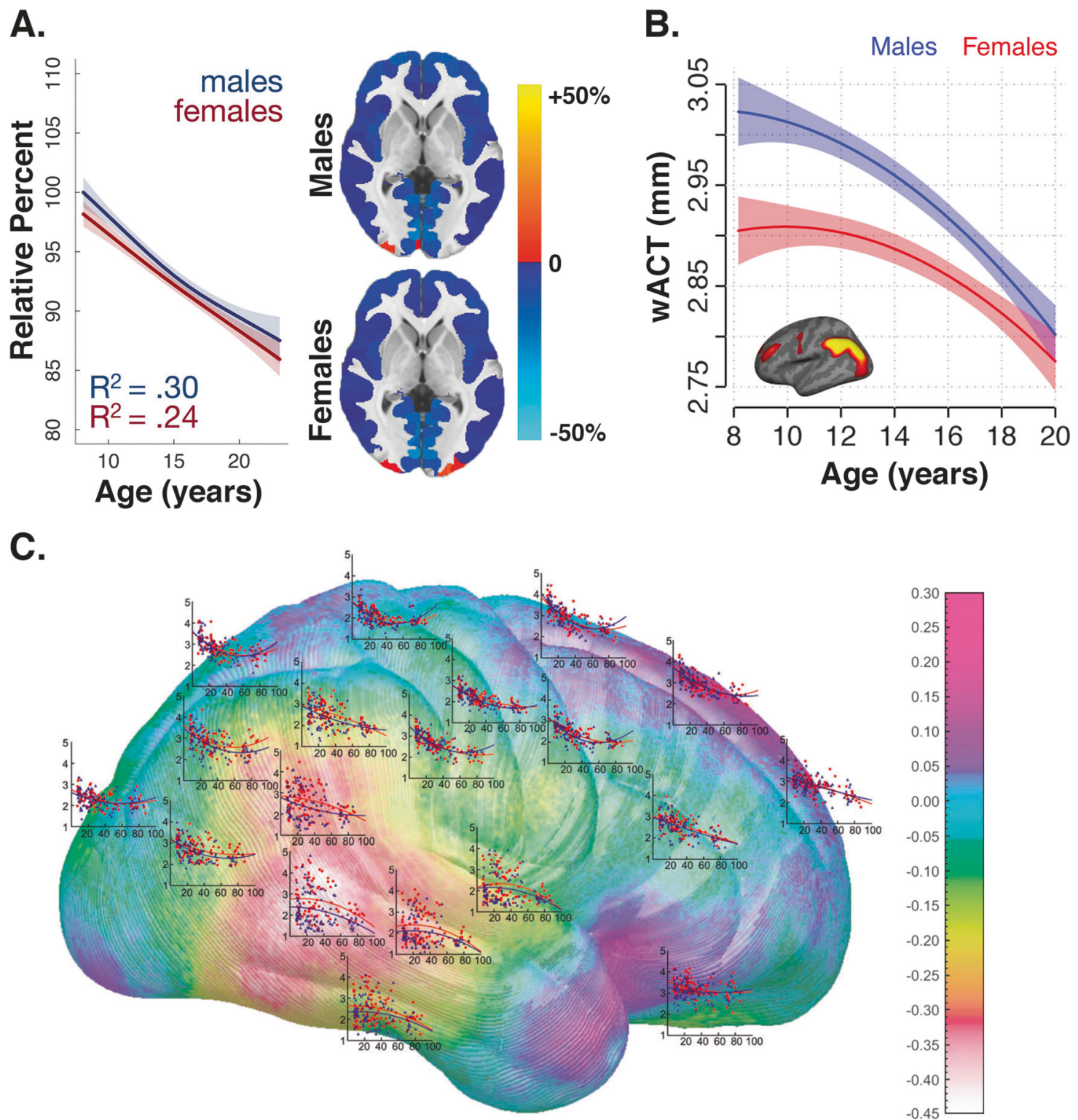

Fig. 3 Sex differences in cortical thickness in youth vary depending on brain region. a Global cortical thickness decreases over the developmental age range in both male and female youth (adapted with permission from ref. [21]). b Age-related changes in cortical thickness within structural covariance networks vary substantially between males and females. For example, males display thicker parietal cortex at younger ages, but nearly equivalent cortex by adulthood (adapted with permission from ref. [60]). $\mathrm{c}$ In a study spanning the lifespan from 7 to 87 years, cortical thickness evolved differently with age in males and females (adapted with permission from ref. [15])

however, this was shown in a cross-sectional sample of adults. Leveraging a cross-sectional sample of 442 individuals ages 8 to 30 years, males showed larger cortical surface area up to age 15 compared to females [47]. Furthermore, in a large longitudinal sample of youth, females attained their peak cortical surface area earlier than males [27]. In terms of gyrification in adults, males showed greater cortical gyrification in most areas of the cortex; however, this pattern was attenuated and even reversed in some regions after controlling for cortical volume in a cross-sectional study [66]. In a cross-sectional sample of individuals ages 5 to 25 years, cortical gyrification was found to be significantly greater in typically developing males than females [67]. Furthermore, these sex differences in gyrification are apparent early in development. A study with 219 longitudinal neuroimaging scans collected from infancy to 2 years of age revealed that males have greater gyrification indices than females by the second year of life, even after controlling for total brain volume [68]. Overall, there is evidence of sex differences in both cortical surface area and gyrification.

\section{SEX DIFFERENCES IN WHITE MATTER ORGANIZATION: DIFFUSION IMAGING}

Diffusion imaging is a neuroimaging technique that uses information about the restriction of the movement of water molecules to estimate the location, orientation, and anisotropy (direction) of white matter tracts [69]. White matter tracts are composed of neurons and myelinated axons which increase the speed and transmission of electrical nerve signals [17]. Bundled myelinated axons allow for the diffusion of water molecules along their main direction but restrict diffusion radially along the tract. These different characteristics can be measured with diffusion imaging [69]. Unlike gray matter volume, which peaks between ages 8 to 10 [26], white 
A.
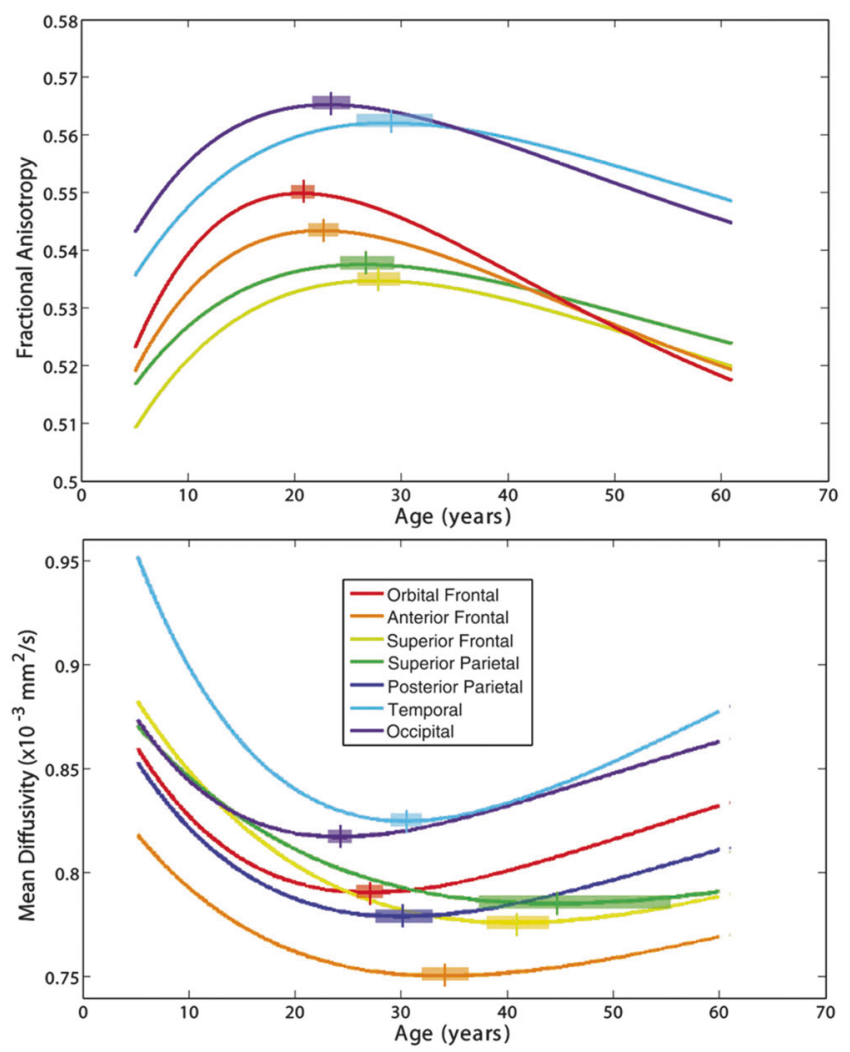

B.

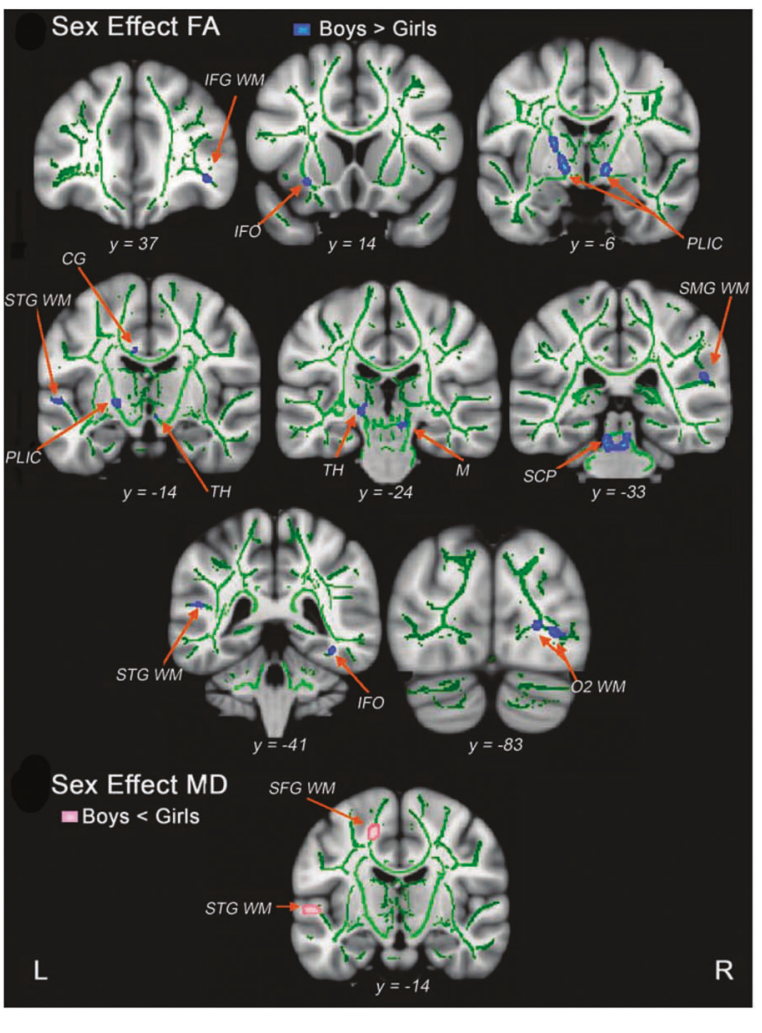

Fig. 4 Males show higher fractional anisotropy and lower mean diffusivity than females. a Best fit curves for fractional anisotropy (FA) and mean diffusivity (MD) by age reveal that FA increases with age until adulthood and then declines thereafter, while MD decreases during development and then begins to increase later in life (adapted with permission from ref. [73]). $\mathbf{b}$ Male youth show higher fractional anisotropy and lower mean diffusivity than females in key regions (adapted with permission from ref. [80])

matter tracts continue to develop well into adulthood up until the late $30 \mathrm{~s}$ [70].

Two commonly reported parameters of diffusion tensor imaging are fractional anisotropy and mean diffusivity. Fractional anisotropy describes the degree of anisotropy or the direction of the diffusion of water molecules. Fractional anisotropy has a value between 0 and 1 , with zero indicating isotropic diffusion (unrestricted or equally restricted in all directions) and is linked to axon packing and myelination [69]. Mean diffusivity is a scalar measure of the total diffusion within a voxel and thus reflects water content and density in white matter [69]. Across childhood, adolescence, and young adulthood, nonlinear changes in these measures are apparent. Fractional anisotropy in white matter generally increases during development while mean white matter diffusivity decreases, with more rapid changes apparent at earlier ages [28, 71, 72]. Specifically, best fit curves for fractional anisotropy and mean diffusivity by age reveal that fractional anisotropy increases with age until adulthood and then declines thereafter, while mean diffusivity decreases during development and then begins to increase later in life [73] (Fig. 4a).

There is evidence of differential development of white matter tracts in males and females. Males show higher fractional anisotropy and lower mean diffusivity in many regions compared to females in adulthood [24, 74-76]. An exception may be higher fractional anisotropy in females compared to males in parts of the corpus callosum [28, 77, 78]. Higher fractional anisotropy and lower mean diffusivity in males compared to females has been shown in youth as well $[28,73,79,80]$ (Fig. 4b). Furthermore, these sex differences in white matter organization have been tied to hormonal levels. Greater testosterone in male youth predicts greater fractional anisotropy, whereas estradiol showed a negative relationship with fractional anisotropy in female youth [80]. However, findings are not uniform: cross-sectional studies either find that females show higher fractional anisotropy then males [81] or they do not find sex differences in fractional anisotropy in youth [82]. In a longitudinal sample of 128 youth 8-28 years of age, males showed lower levels of fractional anisotropy in childhood, equivalents levels in adolescence, and greater levels in adulthood when compared to females [71]. Such interactions between age and sex could explain the inconsistent sex differences observed by other studies. However, another longitudinal study in youth did not find sex differences in the development of white matter tracts [72]. These divergent results emphasize the need for larger diffusion imaging studies with longitudinal follow-up.

\section{SEX DIFFERENCES IN PERFUSION: CEREBRAL BLOOD FLOW}

Cerebral blood flow refers to the movement of blood through the vascular network that supplies the brain. Cerebral blood flow is closely tied to regional metabolism [83, 84]. Neural activity generates metabolic demands for oxygen and glucose, causing increased blood flow to the tissue. Cerebral blood flow is typically defined as the volume of blood that passes through a given amount of brain tissue per unit of time [83]. Originally, cerebral blood flow was measured with positron emission tomography (PET), which involves injecting radioactive tracers into the blood and measuring the signal as the tracers move through the bloodstream. However, the use of radioactive isotopes has made PET prohibitive to use in pediatric populations. Regional cerebral blood flow in the brain can be quantified noninvasively using arterial spin labeled (ASL) perfusion MRI [84]. ASL utilizes water in 
A.
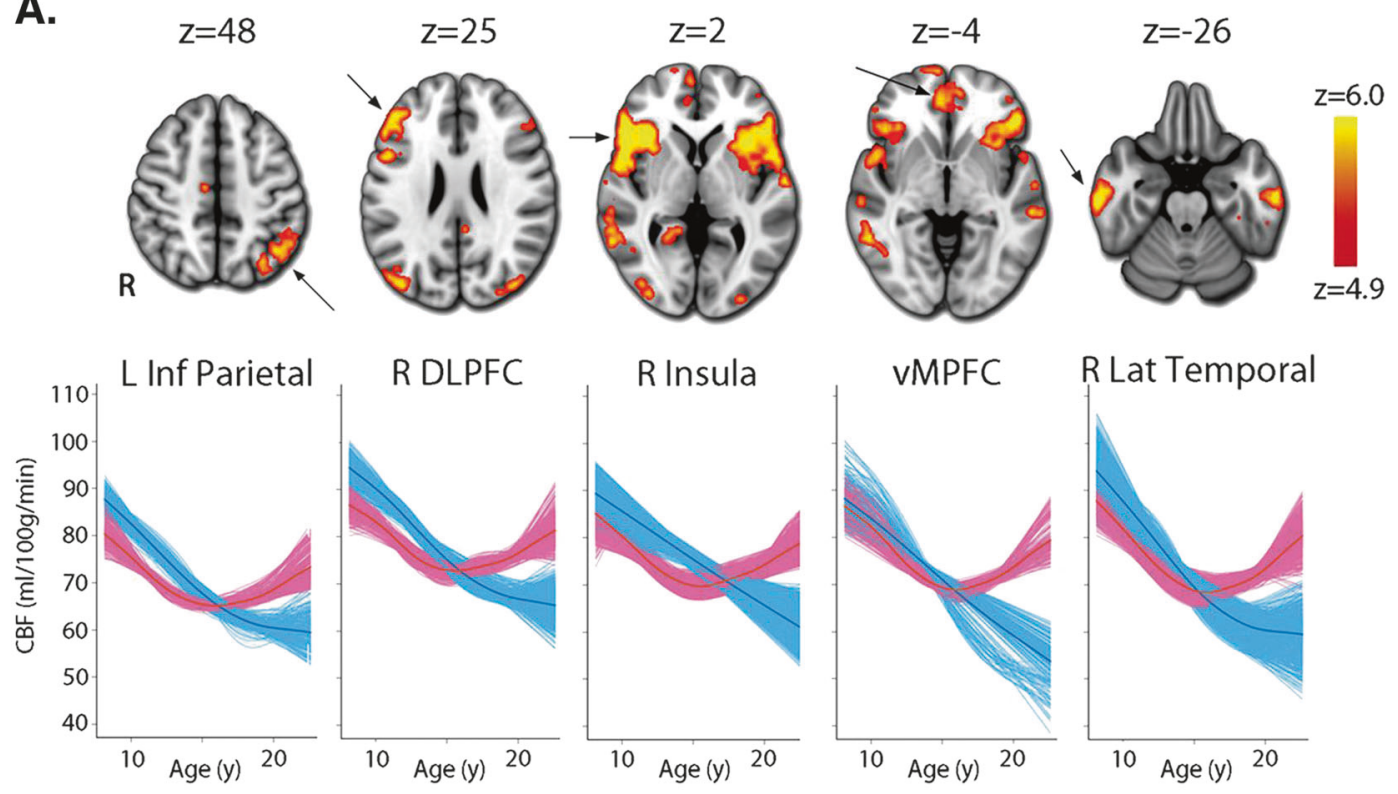

B.

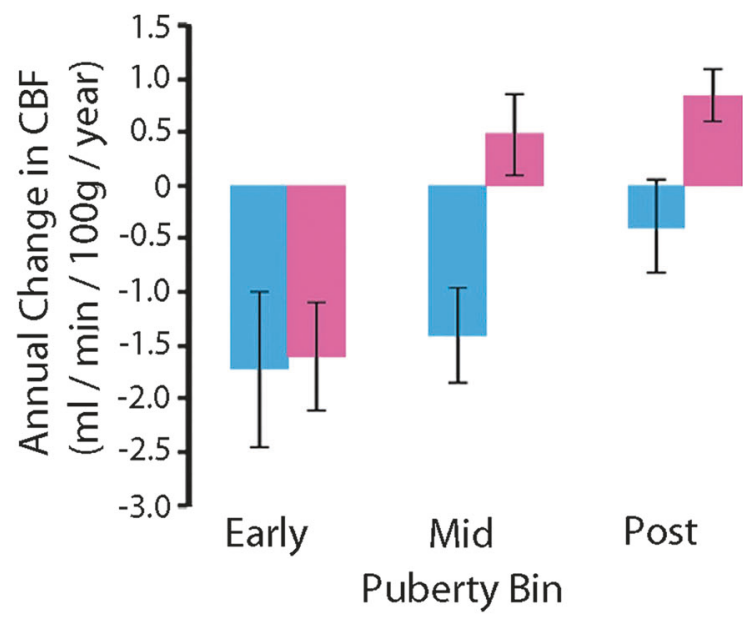

C.

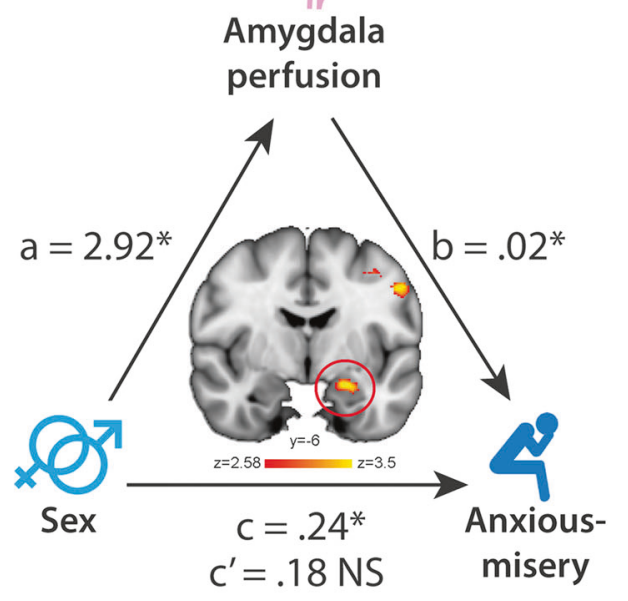

Fig. 5 Cerebral blood flow (CBF) shows marked developmental sex differences. a CBF declines in males (blue) until late adolescence, while $\mathrm{CBF}$ in females (pink) declines until mid-adolescence and then increases thereafter. $\mathbf{b}$ Age-related differences in CBF diverge in males (blue) and females (pink) with advancing pubertal development ( $\mathbf{a}$ and $\mathbf{b}$ adapted with permission from ref. [92]). $\mathbf{c}$ Higher anxious-misery symptoms in post-pubertal females are mediated in part by higher perfusion in the left amygdala (adapted with permission from ref. [120])

arterial blood as an endogenous tracer. ASL leverages a simple fact of anatomy-all blood traveling to the head has to pass through the neck. By applying a magnetic pulse to the neck to tag water in arterial blood in transit, ASL allows the comparison of a tagged image with an untagged image to yield a quantitative measure of cerebral blood flow. Since ASL does not require the use of radioactive tracers like in PET, it is safe to use in studies of children.

The brain consumes approximately 20 percent of the body's energy balance $[85,86]$, and receives $15 \%$ of its cardiac output, despite only representing $2 \%$ of body mass [87]. Blood flow in the brain has been shown to be higher in children compared to adults, with higher levels of blood flow coinciding with periods of rapid brain growth [86, 88]. During normative development, cerebral blood flow declines as youth progress through childhood and adolescence. Wang and colleagues used cross-sectional data to show that youth demonstrate $30 \%$ greater cerebral blood flow than adults and that cerebral blood flow decreased linearly with age [89]. Conversely, another cross-sectional study showed an inverted u-shaped trajectory where total cerebral blood flow increased from 7 months to 6 years of age and then declined thereafter [90]. However, these studies were limited by relatively small sample sizes. In a larger cross-sectional study of 202 children and adolescents, Taki and colleagues demonstrated that this nonlinear pattern varied on a regional basis, with a greater prominence of an inverted u-shaped pattern in many higher-order frontal and parietal regions [91].

Additional evidence for nonlinear changes in blood flow during development was provided by a large cross-sectional study of 922 children, adolescents, and young adults ages 8-22 years [92]. Results demonstrated that gray matter cerebral blood flow showed a rapid decline in late childhood and early adolescence and then plateaued in mid-adolescence before showing a slight increase in early adulthood [92]. The greatest age-related declines in cerebral blood flow were seen in regions of the default mode network (posterior cingulate cortex, ventromedial prefrontal 
cortex, inferior parietal lobule, and lateral temporal cortex) and the executive network such as the frontal pole and dorsolateral prefrontal cortex [92].

Sex differences in cerebral blood flow are well-documented. Several studies have demonstrated that adult females show greater cerebral blood flow than males [93-97]. Taki and colleagues demonstrated that this difference is present even in adolescence, with females having higher blood flow in the posterior cingulate [91]. Males and females also differ in the trajectory of cerebral blood flow changes. Satterthwaite and colleagues demonstrated in a large cross-sectional sample of youth that males show a relatively linear decline in cerebral blood flow from age 8 to 22 years, while females initially show a similar decline until mid-adolescence when cerebral perfusion begins to increase [92] (Fig. 5a). This curvilinear pattern in females was apparent across multiple regions of the brain, including the insula, hippocampus, thalamus, precuneus, posterior cingulate cortex, as well as the prefrontal, temporal, and parietal cortices. Sex differences in cerebral blood flow may be tied to pubertal development. Levels of cerebral blood flow were equivalent between males and females in early puberty, but then diverged around mid-puberty [92] (Fig. 5b). Importantly, these marked perfusion differences between males and females suggest cerebral blood flow may be an important brain phenotype for understanding sex differences in normative and non-normative development. Finally, given the dearth of research that integrates structural and metabolic measures (like PET and ASL MRI), studies that investigate sex differences in precise metabolic markers for measuring glucose uptake, such as fluorodeoxyglucose (FDG) PET, will provide fertile ground for future research.

\section{RELEVANCE FOR PSYCHOPATHOLOGY}

There are marked sex differences between males and females in terms of the prevalence and clinical presentation of psychiatric disorders. Males demonstrate a greater prevalence of neuropsychiatric disorders such as autism, attention-deficit/hyperactivity disorder, Tourette's disorder, and conduct disorder [5, 98-100]. Conversely, females demonstrate a greater prevalence of depressive disorders, anxiety disorders, and eating disorders [6, 7, 11]. Although social factors are undoubtedly important, sex differences in brain development during the critical period of youth suggest that some of this differential risk for specific symptoms may be due to differential vulnerabilities of maturing brain circuitry. Below, we review relevant literature for a subset of disorders which have marked sex differences in their prevalence, including anxiety, depression, psychosis, and attention-deficit/hyperactivity disorder (ADHD).

\section{Anxiety}

Anxiety disorders are among the most prevalent mental health diagnoses, with an onset in childhood, a rapid increase in adolescence, and a lifetime prevalence around 25\% [6, 101, 102]. Substantial sex differences in anxiety disorders have been shown worldwide [6], with prevalence rates being almost two-fold greater in females than males across anxiety diagnoses [103]. Specifically, higher rates are seen in females than males in social anxiety disorder, generalized anxiety disorder, panic disorder, agoraphobia, specific phobia, and post-traumatic stress disorder [104-106]. Furthermore, sex differences in anxiety symptoms remain relatively stable or increase across the lifespan and are apparent regardless of socioeconomic status [107, 108]. Given marked sex differences in the prevalence of anxiety disorders, it is important to interpret studies on the neural substrates of anxiety symptoms in the context of these sex differences.

Neural circuits most commonly implicated in anxiety include the salience network, which involves the amygdala, insula, and anterior cingulate cortex, as well regions important for memory such as the hippocampus $[109,110]$. However, the vast majority of neuroimaging studies in anxiety have focused on task-based brain activation measured with functional magnetic resonance imaging [111-113]. Evidence of differences in brain structure associated with anxiety has been less consistent. A meta-analysis of posttraumatic stress disorder studies showed evidence of frontallimbic and hippocampal structural abnormalities [114]. However, a review of structural imaging studies across multiple anxiety disorders revealed overall mixed results, with studies showing both increased and decreased regional volumes that varied across anxiety disorders and within single anxiety diagnoses [115]. Likewise, a mega-analysis of social anxiety studies was unable to replicate previously reported brain structure abnormalities in a number of regions [116]. In contrast, cerebral blood flow shows a more consistent relationship with anxiety. Prior research has demonstrated that anxiety symptoms are associated with greater regional cerebral blood flow in the insula, amygdala, as well as the prefrontal and temporal cortices [117-120]. Thus, cerebral blood flow may be a potentially important brain phenotype for understanding sex differences in anxiety.

Sex differences in brain perfusion associated with anxiety symptoms have been reported. Under stressful conditions, males showed increased cerebral blood flow in the right prefrontal cortex and reduced perfusion in the left orbitofrontal cortex [121]. Conversely, females under the same stressful conditions showed increased cerebral blood flow in the ventral striatum, putamen, insula, and cingulate cortex [121]. In addition, harm avoidance (a personality trait associated with anxiety) is negatively correlated with cerebral blood flow in the anterior portion of the ventromedial prefrontal cortex in females but not in males [122]. However, these two studies focused on adults only. As noted earlier, females begin to show greater symptoms of anxiety and increased cerebral blood flow around puberty, suggesting that pubertal development is an important period for the emergence of sex differences in affect and perfusion. Amygdala perfusion in particular has been shown to be an important contributor to sex differences in anxious-misery symptoms, which is a combination of anxiety and depressive symptoms. In a large sample of 875 youth, higher anxious-misery levels in post-pubertal females were mediated in part by higher perfusion in the left amygdala (Fig. 5c; [120]). This suggests that greater anxious-misery symptoms in female youth may be driven by excess perfusion in affective brain regions.

\section{Depression}

As with anxiety, females show higher levels of depressive symptoms than males, which becomes more pronounced in late adolescence [101, 103]. By adulthood, the prevalence of major depressive episodes is almost two times higher in females than males worldwide [103, 123]. Among those with depressive symptoms, sex differences in clinical presentations are present. Females endorse more traditional internalizing symptoms of depression while males report greater symptoms of anger/ aggression, substance abuse, and risk-taking behaviors [124, 125]. Additionally, although females have higher rates of suicide attempts [124], males have a higher risk of completed suicide due to the use of more lethal means [126]. Given that the higher prevalence rates of depression in females are fairly consistent worldwide [103] and are stable regardless of different socioeconomic conditions [127], this suggests the possible existence of biological vulnerabilities.

There is an extensive literature on the neurobiological mechanisms associated with depressive symptoms. Early research suggested that major depressive disorder was characterized by para-limbic circuit abnormalities; however, this work was limited by small sample sizes. Compared to healthy controls, metaanalyses have found that individuals with major depressive disorder have smaller volumes in the hippocampus, amygdala, 
striatum, bilateral insula, dorsolateral prefrontal cortex, temporal, and parietal cortices, as well as the dorsomedial and ventromedial prefrontal cortex including the anterior cingulate cortex [128-132]. Furthermore, diffusion tensor imaging studies reveal reduced anisotropy in the frontal and temporal lobes and tracts of those with mood disorders [133-135]. However, the majority of these studies focused on adult populations. Using a longitudinal design in those 12 to 18 years of age, Whittle and colleagues showed that volume alterations in the hippocampus, amygdala, and putamen from early to mid-adolescence were associated with depression onset [136]. Thus, the neural abnormalities associated with depression may become apparent in adolescence.

Whether the neurobiological patterns associated with depressive symptoms differ between males and females is less clear. Schmaal and colleagues conducted a recent meta-analysis that did not find sex by diagnosis interactions for any subcortical brain volumes [130], similar to prior cortical volume and diffusion imaging meta-analyses [132, 134]. Other meta-analyses did not test for sex differences $[128,129]$. Conversely, one meta-analysis of gray matter volume differences in major depressive disorder reported smaller prefrontal cortex volumes in studies with fewer male patients [131]; however, it is unclear whether this is due to differences in global brain size between males and females. In terms of adolescent samples, Whittle and colleagues found divergent patterns of brain development between males and females in a longitudinal study of youth with depressive symptoms. The authors found that depression was associated with greater amygdala growth in females but attenuated growth in males [136]. Furthermore, depressive symptoms were also associated with smaller nucleus accumbens volumes over time in females but not males [136]. The relative sparsity of focused studies emphasizes that research on sex differences in brain development in youth with depressive symptoms is an important area for future work.

\section{Psychosis}

Although large epidemiological studies do not reliably find substantial differences between males and females in terms of the overall prevalence of psychosis $[137,138]$, sex differences have been reported in the clinical presentation and outcomes of psychotic disorders. Females show a slightly later age of onset for psychosis symptoms in young adulthood and show a second peak of onset between 45 and 50 years [139], while early onset psychosis (before age 18 years) is more common in males [140]. Affective symptoms are more commonly reported in females with psychosis spectrum disorders while negative symptoms are more common in males [141, 142]. Furthermore, males with a diagnosis of schizophrenia are at higher risk of suicide, have more hospitalizations, experience longer hospital stays, and show worse social functioning than females with the same diagnosis [143-145]. Given these sex differences in clinical presentation, it is possible that psychosis-spectrum symptoms in males and females are linked to different brain abnormalities as well.

The relationship between psychosis and brain development has been widely studied. One of the most consistent results is the finding of smaller brain volumes in both adults and youth with psychosis symptoms compared to healthy controls [146-149]. In terms of regional volumes, multiple meta-analyses and large scale studies have shown that psychosis is most commonly associated with reduced volumes in the hippocampus, insula, anterior cingulate, superior temporal gyrus, medial temporal lobe, caudate, thalamus, amygdala, and accumbens [148-151], with volume reductions in the caudate nucleus and thalamus being more pronounced in antipsychotic-naïve individuals than those on medication [149]. Using advanced multivariate analysis tools and data from 440 patients with schizophrenia and 501 controls, Rozycki and colleagues found a pattern of widespread regional gray matter volume reductions in regions such as the medial prefrontal, temporolimbic, and peri-Sylvian cortex, as well as enlargement of the ventricles and pallidum [152]. Beyond volumetric measures, similar regions also show reduced gray matter density in psychosis including bilateral insular cortex, anterior cingulate, left parahippocampal gyrus, left middle frontal gyrus, post-central gyrus, and thalamus $[153,154]$.

A number of studies report on sex differences in regional volumes associated with psychosis. Meta-analytic studies reveal that males with psychosis symptoms show smaller intracranial volumes [149] and demonstrate more severe gray matter volume deficits in the insula, thalamus, and medial frontal cortex compared to females with psychosis [150]. Other metaanalyses find smaller accumbens and amygdala volumes in psychosis samples with larger proportions of males than females [148]. In regards to white matter, Bora and colleagues found no evidence of sex differences in white matter volumes or white matter tracts in those with psychosis [150]. Likewise, a metaanalysis of white matter microstructural integrity in the corpus callosum found that the effect size between patients with schizophrenia and controls was larger in females than males in this region, but the difference between females and males did not reach significance [155]. Notably, the majority of the participants included in these meta-analyses were adults. Studies on the impact of psychosis on brain development show volume reductions, although attenuated, in similar regions associated with first-episode psychosis or youth at clinical high-risk for developing psychosis [140, 147, 156-159]. However, sex differences in brain regions associated with psychosis may not be as prominent in studies with youth. In a meta-analysis of longitudinal MRI studies in children and adolescents with early onset psychosis, the proportion of males in each study was not found to significantly impact regional brain volume effect sizes [140]. Likewise, a longitudinal sample of youth with childhood-onset schizophrenia found no sex differences for either cortical thickness or subcortical volumes [160]. Moving forward, it will be important for future research to determine when sex differences in regional volumes emerge during development in youth at risk for psychosis symptoms.

\section{Attention-deficit/hyperactivity disorder}

Sex differences in externalizing symptoms have been widely reported. On average, male youth report greater externalizing behavior than females [161]. Epidemiological studies demonstrate that male youth show a greater prevalence of disorders including conduct disorder and attention-deficit/hyperactivity disorder (ADHD) $[5,98]$. Sex differences in ADHD have been widely reported, with males showing a prevalence rate that is 2.4 times greater than females, which persists into adolescence [12]. However, some researchers have suggested that there exists a "gender paradox" that results in more impairment and worse outcomes in females with ADHD, despite their lower prevalence rates in youth [162]. This may be due in part to the reduced rates of identification of ADHD in females [10] or to the greater exposure to genetic and environmental risk factors necessary in order for females to develop the condition [163]. Thus, sex differences provide an important clinical context for the development of ADHD.

A large number of studies examining the neurobiological mechanisms underlying externalizing symptoms have focused on ADHD. Individuals with ADHD show evidence of smaller global brain volumes, especially in the prefrontal cortex [164-168]. Regional volumetric reductions associated with ADHD also include smaller basal ganglia, striatum, cerebellum, as well as smaller parietal and temporal cortices [164, 165, 168]. Smaller volumes in frontal regions and the striatum in particular are thought to be a central feature of ADHD, implicating a compromised frontalstriatal network associated with this disorder [164]. Abnormal development of cortical thickness has also been reported. Makris and colleagues found that adults with ADHD showed greater 
cortical thinning in regions associated with attention and executive functioning including the inferior parietal lobule, dorsolateral prefrontal cortex, and anterior cingulate cortex [169]. However, many of these studies relied on cross-sectional samples. Using longitudinal designs, development of the prefrontal cortex in terms of cortical thickness and surface area has been shown to be delayed in youth with ADHD [170, 171], which persists from childhood to adulthood [172]. Additionally, metaanalyses of diffusion tensor imaging studies in ADHD find decreased fractional anisotropy in tracts linking cognitive control and attentional networks [173].

In contrast to the large number of neuroimaging studies in those with ADHD, studies of sex differences in brain abnormalities associated with ADHD are less common. Notably, the majority of studies on brain development in ADHD do not test for sex differences, typically as a result of lack of power due to the small sample sizes of females. The underrepresentation of female youth in these studies makes it difficult to determine whether sex differences are apparent in brain development in ADHD. Of the small number of studies that test for sex differences, Mahone and colleagues showed that female youth with ADHD showed reduced gray matter volume in left lateral premotor cortex; while males showed reduced white matter volume in left medial prefrontal cortex [174]. In a sample of 226 youth ages 8 to 12 years old, Dirlikov and colleagues found that female youth with ADHD showed widely distributed reductions in prefrontal cortex surface area while reduced surface area was restricted to the right anterior cingulate and left medial prefrontal cortex in males with ADHD [175]. Furthermore, male youth with ADHD showed reduced total premotor cortex surface area while females did not [175]. Others do not find differences between male and female youth with ADHD in terms of developmental growth patterns in brain volumes [166] or cortical thickness [172]. Given that female youth are underrepresented in studies on ADHD [164, 165], this highlights the need for future work to include sufficient numbers of females in order to evaluate sex differences.

\section{FUTURE RESEARCH DIRECTIONS}

Taken together, the existing literature suggests that sex differences in brain structure, organization, and perfusion are present across the lifespan, and may evolve dynamically during youth. Dissimilarities between males and females are seen in structure, such as volume, gray matter density, cortical thickness, cortical surface area, and gyrification, as well as in the organization of white matter tracts and in cerebral blood flow. There is some evidence that these differences emerge at different times in males and females. These differences are consistent with the robust findings of dissimilarities in symptom prevalence and clinical presentation in males and females in psychiatric disorders, and suggest a possible developmental mechanism for the emergence of such symptoms. However, as highlighted below, there are several outstanding gaps in the literature which could be profitably filled by future research.

Prior work on sex differences in brain development has been limited by small sample sizes and unbalanced groups. While small sample sizes were pervasive in early neuroimaging research, larger samples are increasingly becoming more common. However, sample size continues to be relevant to sex differences research, as examining differences between males and females effectively cuts one's power in half. This is particularly challenging in studies of brain development that are not just examining main effects of sex but attempting to chart sex differences across a range of ages. Likewise, sex difference analyses are sometimes conducted as an afterthought in highly unbalanced groups of males and females. Imbalance is most common in studies where strong sex differences in prevalence rates are apparent, for example, in studies of ADHD. Given the higher variability often seen in the smaller group, if uncorrected, imbalance has the potential to reduce power and potentially yield spurious results if Type I error is not adequately accounted for. Such concerns about power and imbalance are beginning to be mitigated by the rise of large-scale studies of brain development that are publicly available. These include resources such as the NKI-Rockland Sample [176], the Philadelphia Neurodevelopmental Cohort [177], the Pediatric, Imaging, Neurocognition, and Genetics study [178], the Human Connectome Project-Lifespan studies [179], the Healthy Brain Network [180], and the Adolescent Brain Cognitive Development Study [181].

Future work on sex differences in brain development would also benefit from moving beyond cross-sectional designs, which rely on collecting data at one time point in multiple age bins. Cross-sectional studies are limited in their ability to make claims about age-related changes due to potential confounding of developmental processes with cohort measurement error [71]. Longitudinal studies that track developmental processes in the same individuals over time have become more commonplace in recent years. Such studies can model linear and non-linear changes across development with greater confidence that such changes are not due to spurious cohort differences. Although longitudinal designs are more time-consuming and expensive than cross-sectional studies, the advantage of being able to measure temporal changes while controlling for cohort variation is rapidly making longitudinal designs the gold-standard for research on developmental processes [182].

Prior developmental work has also been limited by studies that sample a restricted age range. Development is a dynamic period which does not necessarily progress at the same time in different individuals [183, 184]. The onset of puberty, for example, is later in males than females $[22,185,186]$. Pubertal maturation and changing levels of hormones may be important factors that contribute to sex differences in brain development $[2,3,184,187$, 188]. Puberty is characterized by the influx of hormones, with testosterone and estradiol increasing in both males and females, but males show greater testosterone and females show higher estradiol levels relative to each other [184]. However, although sex differences in the timing of brain development have been reported (e.g., cortical surface area peaks earlier in females than males), it remains unknown if these differences are specifically related to pubertal development. Thus, future work will benefit from capturing neurobiological changes associated with puberty in both sexes using longitudinal designs. Given the potential importance of pubertal development on sex differences in the brain, additional studies are needed that also examine the role of hormonal correlates of brain development and how these effects may differ in males and females.

Additionally, a limitation specific to the psychopathology literature reviewed is the reliance on categorical diagnoses analyzed using case-control designs (e.g., a disordered group vs. control group) rather than using dimensional symptoms. Dimensional measures may be advantageous over categorical approaches because they capture the full spectrum of symptoms including subthreshold symptoms, which are typically disregarded in case-control studies. Dimensional measures are also more representative of the actual presentation of clinical symptoms in the population, which exist on a continuum from healthy to disordered. Notably, measuring the full range of symptoms will require sampling a larger number of individuals instead of only recruiting those with either clinically significant or very low levels of the symptoms of interest. There is a reproducibility crisis in psychiatric neuroimaging research, which may be due in part to the tendency for neuroimaging studies to recruit highly selective samples that are not representative of the population and that under-sample individuals with common comorbidities [189]. Adding to this challenge is the realization that sex differences may modify the dimensional substructure of psychopathology, as 
well as the magnitude, direction, and/or spatial distribution of brain-behavior relationships. Thus, as a result of having such a large potential search space, it will be important for researchers to carefully document the rationalization for the analyses they run, to avoid capitalizing on chance findings. Although this concern is not exclusive to psychiatric neuroimaging, it exemplifies the need to re-conceptualize psychopathology study design and analysis approaches in order to increase the reliability of neuroimaging findings.

One potential obstacle to research regarding sex differences is that it is usually impossible to disentangle biological sex differences from those which could be the result of environmental influences during development (e.g., differences in the social milieu). However, studies of sex chromosome aneuploidy allow for the impact of varying levels of sex chromosome doses ( $X X, X Y$, $X X X, X X Y, X Y Y, X X Y Y, X X X X Y$ ) to be measured. In one such study, Mankiw and colleagues found differences in cerebellar volumes as a function of sex and sex-chromosome aneuploidy [190]. Importantly, the authors developed a novel allometric method to correct for total brain volume effects. In contrast to traditional total brain volume correction methods that assume linear scaling which may invert or exaggerate subcortical sex differences [190], allometric scaling uses normative scaling rules to help us compare the size of one region to the size of the whole brain across individuals with different sized brains. Allometric norms allow researchers to distinguish whether sex differences in brain volume result from regional differences in scaling or if these differences represent deviation from the norm given differences in total brain size. Using such scaling, the authors found that cerebellar subcomponents were sensitive to sex and sex chromosome dose, suggesting a novel method for accounting for global sex differences in brain size beyond simply adding total brain volume or intracranial volume as a covariate [190].

Finally, although there are group average differences between males and females in terms of brain development, no assumptions should be drawn from these differences in terms of the relative capacities of males or females. Importantly, we do not suggest in this review that the human brain is "sexually dimorphic," which implies that male and female brains are distinct. Rather, the high degree of overlap between distributions of males and females argues against a dimorphic view of the human brain. For example, in the largest structural MRI sample to date (over 5000 adults), the authors note that there was a large degree of overlap between males and females on all brain measures assessed [24]. A lack of distinction between the distributions of males and females suggests that individual differences may be especially important. As noted in previous work, the human brain consists of a "mosaic" of features, with the relative proportion of male, female, and unisex attributes varying substantially between individuals [191]. Thus, future work would benefit from exploring interactions with sex to better understand the individual differences that contribute to the high degree of overlap between males and females.

Taken together, relative to the number of neuroimaging studies on brain development, historically there has been much less emphasis on studies examining sex differences in the brain [192]. Prior assumptions that sex differences are negligible or inconsequential are rapidly changing [191, 192]. Given the increasing interest in precision medicine, it is critical that we understand differences in brain structure, organization, and perfusion in males and females. Recognizing the need for a programmatic approach to stimulate sex differences research, the National Institutes of Health's strategic research priorities currently emphasize the importance of understanding sex differences in health and disease [193]. In particular, research focused on developmental sex differences has the potential to advance our understanding of the many psychiatric disorders that show prominent disparities and emerge during youth.

\section{ACKNOWLEDGEMENTS}

This work was supported by a Research Supplement to Promote Diversity in HealthRelated Research and NIMH grants (grant numbers: R01MH107703 to TDS; R01MH113550 to TDS) and by the Lifespan Brain Institute at the Children's Hospital of Philadelphia and Penn Medicine. Support was also provided by a NARSAD Young Investigator Award (ANK), as well as a Building Interdisciplinary Research Careers in Women's Health (BIRCWH) grant (K12 HD085848) and Penn PROMOTES Research on Sex and Gender in Health grant at the University of Pennsylvania (ANK). This research was funded in part by the Intramural Research Program of the NIMH (Clinical trial reg. no. NCT00001246, clinicaltrials.gov; NIH Annual Report Number, ZIA MH002794, Protocol ID 89-M-0006).

\section{ADDITIONAL INFORMATION}

Competing interests: The authors declare no competing interests.

Publisher's note: Springer Nature remains neutral with regard to jurisdictional claims in published maps and institutional affiliations.

\section{REFERENCES}

1. Schulz KM, Sisk CL. The organizing actions of adolescent gonadal steroid hormones on brain and behavioral development. Neurosci Biobehav Rev. 2016;70:148-58.

2. Sisk CL, Zehr JL. Pubertal hormones organize the adolescent brain and behavior. Front Neuroendocrinol. 2005;26:163-74.

3. Goddings AL, Mills KL, Clasen LS, Giedd JN, Viner RM, Blakemore SJ. The influence of puberty on subcortical brain development. Neuroimage. 2014;88:242-51. Using a longitudinal sample of 711 neuroimaging scans from 275 youth aged 7-20 years, the authors revealed sex differences in the growth trajectories of subcortical structures.

4. Herting MM, Gautam P, Spielberg JM, Kan E, Dahl RE, Sowell ER. The role of testosterone and estradiol in brain volume changes across adolescence: A longitudinal structural MRI study. Hum Brain Mapp. 2014;35:5633-45.

5. Polanczyk G, Silva de Lima M, Horta BL, Biederman J, Rohde LA. The worldwide prevalence of ADHD: A systematic review and metaregression analysis. Am J Psychiatry. 2007;164:942-8.

6. Remes $O$, Brayne $C$, van der Linde R, Lafortune L. A systematic review of reviews on the prevalence of anxiety disorders in adult populations. Brain Behav. 2016;6:1-33.

7. Smink FRE, van Hoeken D, Oldehinkel AJ, Hoek HW. Prevalence and severity of DSM-5 eating disorders in a community cohort of adolescents. Int J Eat Disord. 2014;47:610-9.

8. Beesdo K, Knappe S, Pine DS. Anxiety and anxiety disorders in children and adolescents: Developmental issues and implications for DSM-V. Psychiatr Clin North Am. 2009;32:483-524.

9. Albert PR. Why is depression more prevalent in women? J Psychiatry Neurosci. 2015;40:219-21.

10. Froehlich TE, Lanphear BP, Epstein JN, Barbaresi WJ, Katusic SK, Kahn RS Prevalence, recognition, and treatment of attention-deficit/hyperactivity disorder in a national sample of US children. Arch Pediatr Adolesc Med. 2007;161:857-64.

11. Avenevoli S, Swendsen J, He JP, Burstein M, Merikangas KR. Major depression in the national comorbidity survey-adolescent supplement: Prevalence, correlates, and treatment. J Am Acad Child Adolesc Psychiatry. 2015;54:37-44.

12. Willcutt EG. The prevalence of DSM-IV attention-deficit/hyperactivity disorder: $A$ meta-analytic review. Neurotherapeutics. 2012;9:490-9.

13. Cosgrove K, Mazure C, Staley J. Evolving knowledge of sex differences in brain structure, function, and chemistry. Biol Psychiatry. 2007;62:847-55.

14. Ruigrok ANV, Salimi-Khorshidi G, Lai M-C, Baron-Cohen S, Lombardo MV, Tait RJ, et al. A meta-analysis of sex differences in human brain structure. Neurosci Biobehav Rev. 2014;39:34-50.

15. Sowell ER, Peterson BS, Kan E, Woods RP, Yoshii J, Bansal R, et al. Sex differences in cortical thickness mapped in 176 healthy individuals between 7 and 87 years of age. Cereb Cortex. 2007;17:1550-60.

16. Kersbergen KJ, Makropoulos A, Aljabar P, Groenendaal F, de Vries LS, Counsell $\mathrm{SJ}$, et al. Longitudinal regional brain development and clinical risk factors in extremely preterm infants. J Pediatr. 2016;178:93-100.

17. Stiles J, Jernigan TL. The basics of brain development. Neuropsychol Rev. 2010;20:327-48.

18. Knickmeyer RC, Gouttard S, Kang C, Evans D, Smith JK, Hamer RM, et al. A structural MRI study of human brain development from birth to 2 years. J Neurosci. 2010;28:12176-82. 
19. De Bellis MD, Keshavan MS, Beers SR, Hall J, Frustaci K, Masalehdan A, et al. Sex differences in brain maturation during childhood and adolescence. Cereb Cortex. 2001;11:552-7.

20. Brain Development Cooperative Group. Total and regional brain volumes in a population-based normative sample from 4 to 18 years: The NIH MRI study of normal brain development. Cereb Cortex. 2012;22:1-12. Reports on brain volume data for 325 children, ages 4.5 to 18 years, from the first crosssectional time point of the National Institutes of Health (NIH) Magnetic Resonance Imaging Study of Normal Brain Development.

21. Gennatas ED, Avants BB, Wolf DH, Satterthwaite TD, Ruparel K, Ciric R, et al. Agerelated effects and sex differences in gray matter density, volume, mass, and cortical thickness from childhood to young adulthood. J Neurosci. 2017;37:5065-73. Demonstrated that both total gray matter volume and estimated gray matter mass are greater in males, while females show greater gray matter density using a cross-sectional sample of 1,189 youth ages 8 to 23 years.

22. Bramen JE, Hranilovich JA, Dahl RE, Forbes $E E$, Chen J, Toga AW, et al. Puberty influences medial temporal lobe and cortical gray matter maturation differently in boys than girls matched for sexual maturity. Cereb Cortex. 2011;21:636-46.

23. Luders E, Narr KL, Thompson PM, Woods RP, Rex DE, Jancke L, et al. Mapping cortical gray matter in the young adult brain: Effects of gender. Neuroimage. 2005;26:493-501.

24. Ritchie SJ, Cox SR, Shen X, Lombardo MV, Reus LM, Alloza C, et al. Sex differences in the adult human brain: Evidence from 5,216 UK Biobank participants. Cereb Cortex. 2018. Reported on the largest structural MRI sample to date from the UK Biobank with over 5,000 adults, which revealed sex differences in brain structure and variability.

25. Giedd JN, Blumenthal J, Jeffries NO, Castellanos FX, Liu H, Zijdenbos A, et al. Brain development during childhood and adolescence: A longitudinal MRI study. Nat Neurosci. 1999;2:861-3.

26. Lenroot RK, Gogtay N, Greenstein DK, Wells EM, Wallace GL, Clasen LS, et al. Sexual dimorphism of brain developmental trajectories during childhood and adolescence. Neuroimage. 2007;36:1065-73.

27. Raznahan A, Shaw P, Lalonde F, Stockman M, Wallace GL, Greenstein D, et al. How does your cortex grow? J Neurosci. 2011;31:7174-7. Leveraged over 1,250 longitudinally acquired brain scans from 647 healthy individuals aged 3 to 30 years to show that differences in cortical volumes depend on the complex interaction between cortical thickness, convex hull area, and gyrification.

28. Lebel C, Beaulieu C. Longitudinal development of human brain wiring continues from childhood into adulthood. J Neurosci. 2011;31:10937-47.

29. Whitaker KJ, Vértes PE, Romero-Garcia R, Váša F, Moutoussis M, Prabhu G, et al. Adolescence is associated with genomically patterned consolidation of the hubs of the human brain connectome. Proc Natl Acad Sci. 2016;113:9105-10.

30. Gogtay N, Giedd JN, Lusk L, Hayashi KM, Greenstein D, Vaituzis AC, et al. Dynamic mapping of human cortical development during childhood through early adulthood. Proc Natl Acad Sci. 2004;101:8174-9.

31. Thompson PM, Gledd JN, Woods RP, MacDonald D, Evans AC, Toga AW. Growth patterns in the developing brain detected by using continuum mechanical tensor maps. Nature. 2000;404:190-3.

32. Allen JS, Damasio H, Grabowski TJ, Bruss J, Zhang W. Sexual dimorphism and asymmetries in the gray-white composition of the human cerebrum. Neuroimage. 2003;18:880-94.

33. Goldstein JM, Seidman LJ, Horton NJ, Makris N, Kennedy DN, Caviness VS, et al. Normal sexual dimorphism of the adult human brain assessed by in vivo magnetic resonance imaging. Cereb Cortex. 2001;11:490-7.

34. Gur RC, Turetsky BI, Matsui M, Yan M, Bilker W, Hughett $P$, et al. Sex differences in brain gray and white matter in healthy young adults: Correlations with cognitive performance. J Neurosci. 1999;19:4065-72.

35. Dennison $M$, Whittle $S$, Yücel $M$, Vijayakumar N, Kline A, Simmons J, et al. Mapping subcortical brain maturation during adolescence: Evidence of hemisphere- and sex-specific longitudinal changes. Dev Sci. 2013;16:772-91.

36. Neufang S, Specht K, Hausmann M, Güntürkün O, Herpertz-Dahlmann B, Fink $\mathrm{GR}$, et al. Sex differences and the impact of steroid hormones on the developing human brain. Cereb Cortex. 2009;19:464-73.

37. Filipek PA, Richelme C, Kennedy DN, Caviness VS. The young adult human brain: An MRI-based morphometric analysis. Cereb Cortex. 1994;4:344-60.

38. Giedd JN, Vaituzis AC, Hamburger SD, Lange N, Rajapakse JC, Kaysen D, et al. Quantitative MRI of the temporal lobe, amygdala, and hippocampus in normal human development: Ages 4-18 years. J Comp Neurol. 1996;366:223-30.

39. Li J, Chen C, Lei X, Wang Y, Chen C, He Q, et al. The NTSR1 gene modulates the association between hippocampal structure and working memory performance. Neuroimage. 2013;75:79-86
40. Suzuki M, Hagino H, Nohara S, Zhou SY, Kawasaki Y, Takahashi T, et al. Malespecific volume expansion of the human hippocampus during adolescence. Cereb Cortex. 2005;15:187-93.

41. Cherbuin N, Windsor TD, Anstey KJ, Maller JJ, Meslin C, Sachdev PS. Hippocampal volume is positively associated with behavioural inhibition (BIS) in a large community-based sample of mid-life adults: The PATH through life study. Soc Cogn Affect Neurosci. 2008;3:262-9.

42. Fjell AM, Westlye LT, Amlien I, Espeseth T, Reinvang I, Raz N, et al. Minute effects of sex on the aging brain: A multisample magnetic resonance imaging study of healthy aging and Alzheimer's disease. J Neurosci. 2009;29:8774-83.

43. Jäncke $L$, Mérillat $S$, Liem F, Hänggi J. Brain size, sex, and the aging brain. Hum Brain Mapp. 2015;36:150-69.

44. Marwha D, Halari M, Eliot L. Meta-analysis reveals a lack of sexual dimorphism in human amygdala volume. Neuroimage. 2017;147:282-94.

45. Tan A, Ma W, Vira A, Marwha D, Eliot L. The human hippocampus is not sexuallydimorphic: Meta-analysis of structural MRI volumes. Neuroimage. 2016;124:350-66.

46. Satterthwaite TD, Vandekar S, Wolf DH, Ruparel K, Roalf DR, Jackson C, et al. Sex differences in the effect of puberty on hippocampal morphology. J Am Acad Child Adolesc Psychiatry. 2014b;53:341-50.

47. Koolschijn PCMP, Crone EA. Sex differences and structural brain maturation from childhood to early adulthood. Dev Cogn Neurosci. 2013;5:106-18.

48. Wierenga LM, Sexton JA, Laake P, Giedd JN, Tamnes CK. A Key Characteristic of sex differences in the developing brain: Greater variability in brain structure of boys than girls. Cereb Cortex. 2017. Leveraged a cross-sectional sample of over 1,000 youth, 3 to 21 years of age, to reveal that males show significantly greater variance than females in a number of structures, beyond differences in mean volumes.

49. Good CD, Johnsrude I, Ashburner J, Henson RNA, Friston KJ, Frackowiak RSJ. Cerebral asymmetry and the effects of sex and handedness on brain structure: $A$ voxel-based morphometric analysis of 465 normal adult human brains. Neuroimage. 2001;14:685-700.

50. Fischl B, Dale AM. Measuring the thickness of the human cerebral cortex from magnetic resonance images. Proc Natl Acad Sci. 2000;97:11050-5.

51. White T, Su S, Schmidt M, Kao CY, Sapiro G. The development of gyrification in childhood and adolescence. Brain Cogn. 2010;72:36-45.

52. Amlien IK, Fjell AM, Tamnes CK, Grydeland H, Krogsrud SK, Chaplin TA, et al. Organizing principles of human cortical development-thickness and area from 4 to 30 years: Insights from comparative primate neuroanatomy. Cereb Cortex. 2016;26:257-67.

53. Shaw P, Kabani NJ, Lerch JP, Eckstrand K, Lenroot R, Gogtay N, et al. Neurodevelopmental trajectories of the human cerebral cortex. J Neurosci. 2008;28:3586-94.

54. Mutlu AK, Schneider M, Debbané M, Badoud D, Eliez S, Schaer M. Sex differences in thickness, and folding developments throughout the cortex. Neuroimage. 2013;82:200-7.

55. van Soelen ILC, Brouwer RM, van Baal GCM, Schnack HG, Peper JS, Collins DL, et al. Genetic influences on thinning of the cerebral cortex during development. Neuroimage. 2012;59:3871-80.

56. Tamnes CK, Østby Y, Fjell AM, Westlye LT, Due-Tønnessen P, Walhovd KB. Brain maturation in adolescence and young adulthood: Regional age-related changes in cortical thickness and white matter volume and microstructure. Cereb Cortex. 2010;20:534-48.

57. Ducharme S, Albaugh MD, Nguyen TV, Hudziak JJ, Mateos-Pérez JM, Labbe A, et al. Trajectories of cortical thickness maturation in normal brain developmentthe importance of quality control procedures. Neuroimage. 2016;125:267-79.

58. Sowell ER. Longitudinal mapping of cortical thickness and brain growth in normal children. J Neurosci. 2004;24:8223-31.

59. Vandekar SN, Shinohara RT, Raznahan A, Roalf DR, Ross M, DeLeo N, et al. Topologically dissociable patterns of development of the human cerebral cortex. J Neurosci. 2015;35:599-609.

60. Sotiras A, Toledo JB, Gur RE, Gur RC, Satterthwaite TD, Davatzikos C. Patterns of coordinated cortical remodeling during adolescence and their associations with functional specialization and evolutionary expansion. Proc Natl Acad Sci. 2017;114:3527-32.

61. Muftuler LT, Davis EP, Buss C, Head K, Hasso AN, Sandman CA. Cortical and subcortical changes in typically developing preadolescent children. Brain Res. 2011;1399:15-24.

62. Maingault S, Tzourio-Mazoyer N, Mazoyer B, Crivello F. Regional correlations between cortical thickness and surface area asymmetries: A surface-based morphometry study of 250 adults. Neuropsychologia. 2016;93:350-64.

63. Winkler AM, Kochunov P, Blangero J, Almasy L, Zilles K, Fox PT, et al. Cortical thickness or grey matter volume? The importance of selecting the phenotype for imaging genetics studies. Neuroimage. 2010;53:1135-46. 
64. Chen C-H, Fiecas M, Gutierrez ED, Panizzon MS, Eyler LT, Vuoksimaa E, et al. Genetic topography of brain morphology. Proc Natl Acad Sci. 2013;110:17089-94.

65. Su S, White T, Schmidt M, Kao CY, Sapiro G. Geometric computation of human gyrification indexes from magnetic resonance images. Hum Brain Mapp. 2013;34:1230-44.

66. Gautam P, Anstey KJ, Wen W, Sachdev PS, Cherbuin N. Cortical gyrification and its relationships with cortical volume, cortical thickness, and cognitive performance in healthy mid-life adults. Behav Brain Res. 2015;287:331-9.

67. Fish AM, Cachia A, Fischer C, Mankiw C, Reardon PK, Clasen LS, et al. Influences of brain size, sex, and sex chromosome complement on the architecture of human cortical folding. Cereb Cortex. 2017;27:5557-67.

68. Li G, Wang L, Shi F, Lyall AE, Lin W, Gilmore JH, et al. Mapping longitudinal development of local cortical gyrification in infants from birth to 2 years of age. J Neurosci. 2014;34:4228-38.

69. Alexander AL, Lee JE, Lazar M, Field AS. Diffusion tensor imaging of the brain. Neurotherapeutics. 2007:4:316-29.

70. Grydeland H, Walhovd KB, Tamnes CK, Westlye LT, Fjell AM. Intracortical myelin links with performance variability across the human lifespan: Results from T1and T2-weighted MRI myelin mapping and diffusion tensor imaging. J Neurosci. 2013;33:18618-30.

71. Simmonds DJ, Hallquist MN, Asato M, Luna B. Developmental stages and sex differences of white matter and behavioral development through adolescence: A longitudinal diffusion tensor imaging (DTI) study. Neuroimage 2014;92:356-68.

72. Krogsrud SK, Fjell AM, Tamnes CK, Grydeland H, Mork L, Due-Tønnessen $P$, et al. Changes in white matter microstructure in the developing brain- $A$ longitudinal diffusion tensor imaging study of children from 4 to 11years of age. Neuroimage. 2016;124:473-86.

73. Lebel C, Caverhill-Godkewitsch S, Beaulieu C. Age-related regional variations of the corpus callosum identified by diffusion tensor tractography. Neuroimage. 2010;52:20-31.

74. Abe $\mathrm{O}$, Yamasue $\mathrm{H}$, Yamada $\mathrm{H}$, Masutani $\mathrm{Y}$, Kabasawa $H$, Sasaki $H$, et al. Sex dimorphism in gray/white matter volume and diffusion tensor during normal aging. NMR Biomed. 2010;23:446-58.

75. Westerhausen R, Walter C, Kreuder F, Wittling RA, Schweiger E, Wittling W. The influence of handedness and gender on the microstructure of the human corpus callosum: A diffusion-tensor magnetic resonance imaging study. Neurosci Lett. 2003;351:99-102.

76. Hsu JL, Leemans A, Bai CH, Lee CH, Tsai YF, Chiu HC, et al. Gender differences and age-related white matter changes of the human brain: A diffusion tensor imaging study. Neuroimage. 2008;39:566-77.

77. Schmithorst VJ, Holland SK, Dardzinski BJ. Developmental differences in white matter architecture between boys and girls. Hum Brain Mapp. 2008;29:696-710.

78. Kanaan RA, Chaddock C, Allin M, Picchioni MM, Daly E, Shergill SS, et al. Gender influence on white matter microstructure: A tract-based spatial statistics analysis. PLoS One. 2014;9:1-6.

79. Clayden JD, Jentschke S, Munoz M, Cooper JM, Chadwick MJ, Banks T, et al. Normative development of white matter tracts: Similarities and differences in relation to age, gender, and intelligence. Cereb Cortex. 2012;22:1738-47.

80. Herting MM, Maxwell EC, Irvine C, Nagel BJ. The impact of sex, puberty, and hormones on white matter microstructure in adolescents. Cereb Cortex. 2012;22:1979-92.

81. Bava S, Boucquey V, Goldenberg D, Thayer RE, Ward M, Jacobus J, et al. Sex differences in adolescent white matter architecture. Brain Res. 2011;1375:41-8.

82. Eluvathingal TJ, Hasan KM, Kramer L, Fletcher JM, Ewing-cobbs L. Quantitative diffusion tensor tractography of association and projection fibers in normally developing children and adolescents. Cereb Cortex. 2007;17:2760-8.

83. Petrella JR, Provenzale JM. MR perfusion imaging of the brain: Techniques and applications. Am J Roentgenol. 2000;175:207-19.

84. Detre JA, Wang J, Wang Z, Rao H. Arterial spin-labeled perfusion MRI in basic and clinical neuroscience. Curr Opin Neurol. 2009;22:348-55.

85. Magistretti PJ, Allaman I. A cellular perspective on brain energy metabolism and functional imaging. Neuron. 2015;86:883-901.

86. Epstein HT. Stages of increased cerebral blood flow accompany stages of rapid brain growth. Brain Dev. 1999;21:535-9.

87. Bouma GJ, Muizelaar JP. Relationship between cardiac output and cerebral blood flow in patients with intact and with impaired autoregulation. J Neurosurg. 1990;73:368-74.

88. Takahashi T, Shirane R, Sato S, Yoshimoto T. Developmental changes of cerebral blood flow and oxygen metabolism in children. Am J Neuroradiol. 1999;20:917-22.

89. Wang J, Licht DJ, Jahng G-H, Liu C-S, Rubin JT, Haselgrove J, et al. Pediatric perfusion imaging using pulsed arterial spin labeling. J Magn Reson Imaging. 2003;18:404-13.
90. Wu C, Honarmand AR, Schnell S, Kuhn R, Schoeneman SE, Ansari SA, et al. Agerelated changes of normal cerebral and cardiac blood flow in children and adults aged 7 months to 61 years. J Am Heart Assoc. 2016;5:1-13.

91. Taki Y, Hashizume H, Sassa Y, Takeuchi H, Wu K, Asano M, et al Correlation between gray matter density-adjusted brain perfusion and age using brain MR images of 202 healthy children. Hum Brain Mapp. 2011;32:1973-85.

92. Satterthwaite TD, Shinohara RT, Wolf DH, Hopson RD, Elliott MA, Vandekar SN et al. Impact of puberty on the evolution of cerebral perfusion during adolescence. Proc Natl Acad Sci. 2014a;111:8643-8. Identified marked sex differences in cerebral blood flow in 922 youth ages 8 to 22 years, where males show a relatively linear decline in cerebral blood flow, while females initially show a similar decline until mid-adolescence when cerebral perfusion begins to increase.

93. Liu Y, Zhu X, Feinberg D, Guenther M, Gregori J, Weiner MW, et al. Arterial spin labeling MRI study of age and gender effects on brain perfusion hemodynamics. Magn Reson Med. 2012;68:912-22.

94. Mathew RJ, Wilson WH, Tant SR. Determinants of resting regional cerebral blood flow in normal subjects. Bio Psychiatry. 1986;21:907-14.

95. Rodriguez G, Warkentin S, Risberg J, Rosadini G. Sex differences in regional cerebral blood flow. J Cereb Blood Flow Metab. 1988;8:783-9.

96. Baxter LR, Mazziotta JC, Phelps ME, Selin CE, Guze BH, Fairbanks L. Cerebral glucose metabolic rates in normal human females versus normal males. Psychiatry Res. 1987;21:237-45.

97. Gur RC, Gur RE, Obrist WD, Hungerbuhler JP, Younkin D, Rosen AD, et al. Sex and handedness differences in cerebral blood flow during rest and cognitive activity. Science. 1982;217:659-61.

98. Nock MK, Kazdin AE, Hirpi E, Kessler RC. Prevalence, subtypes, and correlates of DSM-IV conduct disorder in the National Comorbidity Survey Replication. Psychol Med. 2006;36:699.

99. Supekar K, lyer T, Menon V. The influence of sex and age on prevalence rates of comorbid conditions in autism. Autism Res. 2017;10:778-89.

100. Yang J, Hirsch L, Martino D, Jette N, Roberts J, Pringsheim T. The prevalence of diagnosed Tourette syndrome in Canada: A national population-based study. Mov Disord. 2016;31:1658-63.

101. Roza SJ, Hofstra MB, van der Ende J, Verhulst FC. Stable prediction of mood and anxiety disorders based on behavioral and emotional problems in childhood: A 14-year follow-up during childhood, adolescence, and young adulthood. Am J Psychiatry. 2003;160:2116-21.

102. Kessler RC, Chiu WT, Demler O, Walters EE. Prevalence, severity, and comorbidity of 12-month DSM-IV disorders in the national comorbidity survey replication. Arch Gen Psychiatry. 2005;62:617-27.

103. Baxter AJ, Scott KM, Ferrari AJ, Norman RE, Vos T, Whiteford HA. Challenging the myth of an "epidemic" of common mental disorders: Trends in the global prevalence of anxiety and depression between 1990 and 2010. Depress Anxiety. 2014:31:506-16.

104. Bandelow B, Michaelis S. Epidemiology of anxiety disorders in the 21 st century. Dialog Clin Neurosci. 2015;17:327-35.

105. Stein DJ, Lim CCW, Roest AM, de Jonge P, Aguilar-Gaxiola S, Al-Hamzawi A, et al. The cross-national epidemiology of social anxiety disorder: Data from the World Mental Health Survey Initiative. BMC Med. 2017;15:143.

106. Breslau N. The epidemiology of trauma, PTSD, and other posttrauma disorders. Trauma Violence Abus. 2009;10:198-210.

107. Somers JM, Goldner EM, Waraich P, Hsu L. Prevalence and incidence studies of anxiety disorders: A systematic review of the literature. Can J Psychiatry. 2006;51:100-13.

108. Steel Z, Marnane C, Iranpour C, Chey T, Jackson JW, Patel V, et al. The global prevalence of common mental disorders: A systematic review and meta-analysis 1980-2013. Int J Epidemiol. 2014;43:476-93.

109. Sylvester CM, Corbetta M, Raichle ME, Rodebaugh TL, Schlaggar BL, Sheline $\mathrm{YI}$, et al. Functional network dysfunction in anxiety and anxiety disorders. Trends Neurosci. 2012;35:527-35.

110. Damsa C, Kosel M, Moussally J. Current status of brain imaging in anxiety disorders. Curr Opin Psychiatry. 2009;22:96-110.

111. Shin LM, Liberzon I. The neurocircuitry of fear, stress, and anxiety disorders. Neuropsychopharmacology. 2010;35:169-91.

112. Etkin A, Wager TD. Functional neuroimaging of anxiety: A meta-analysis of emotional processing in PTSD, social anxiety disorder, and specific phobia. Am J Psychiatry. 2007;164:1476-88.

113. Fredrikson M, Faria V. Neuroimaging in anxiety disorders. Anxiety Disord. 2013:29:47-66.

114. Karl A, Schaefer M, Malta LS, Dörfel D, Rohleder N, Werner A. A meta-analysis of structural brain abnormalities in PTSD. Neurosci Biobehav Rev. 2006;30:1004-31.

115. Duval ER, Javanbakht A, Liberzon I. Neural circuits in anxiety and stress disorders: A focused review. Ther Clin Risk Manag. 2015;11:115-26. 
116. Bas-Hoogendam JM, van Steenbergen H, Pannekoek JN, Fouche J-P, Lochner C, Hattingh $\mathrm{CJ}$, et al. Voxel-based morphometry multi-center mega-analysis of brain structure in social anxiety disorder. Neuroimage Clin. 2017;16:678-88.

117. Andreescu C, Gross JJ, Lenze E, Edelman KD, Snyder S, Tanase C, et al. Altered cerebral blood flow patterns associated with pathologic worry in the elderly. Depress Anxiety. 2011;28:202-9.

118. Schuff N, Zhang Y, Zhan W, Lenoci M, Ching C, Boreta L, et al. Patterns of altered cortical perfusion and diminished subcortical integrity in posttraumatic stress disorder: An MRI study. Neuroimage. 2011;54:S62-8.

119. Wang J, Rao H, Wetmore GS, Furlan PM, Korczykowski M, Dinges DF, et al. Perfusion functional MRI reveals cerebral blood flow pattern under psychological stress. Proc Natl Acad Sci. 2005;102:17804-9.

120. Kaczkurkin AN, Moore TM, Ruparel K, Ciric R, Calkins ME, Shinohara RT, et al. Elevated amygdala perfusion mediates developmental sex differences in trait anxiety. Biol Psychiatry. 2016;80:775-85. Showed that higher anxious-misery levels in post-pubertal females were mediated in part by higher perfusion in the left amygdala in a large sample of 875 youth.

121. Wang J, Korczykowski M, Rao H, Fan Y, Pluta J, Gur RC, et al. Gender difference in neural response to psychological stress. Soc Cogn Affect Neurosci. 2007;2:227-39.

122. Hakamata $Y$, Iwase $M$, Iwata $H$, Kobayashi T, Tamaki T, Nishio M, et al. Gender difference in relationship between anxiety-related personality traits and cerebral brain glucose metabolism. Psychiatry Res Neuroimaging. 2009;173:206-11.

123. Bromet E, Andrade LH, Hwang I, Sampson NA, Alonso J, de Girolamo G, et al. Cross-national epidemiology of DSM-IV major depressive episode. BMC Med. 2011;9:1-16.

124. Marcus SM, Kerber KB, Rush AJ, Wisniewski SR, Nierenberg A, Balasubramani GK, et al. Sex differences in depression symptoms in treatment-seeking adults: Confirmatory analyses from the sequenced treatment alternatives to relieve depression study. Compr Psychiatry. 2008;49:238-46.

125. Martin LA, Neighbors HW, Griffith DM. The experience of symptoms of depression in men vs women: Analysis of the national comorbidity survey replication. JAMA Psychiatry. 2013;70:1100-6.

126. Curtin SC, Warner M, Hedegaard H. Increase in suicide in the United States, 1999-2014. NCHS Data Brief. 2016;241:1-8.

127. Rai D, Zitko P, Jones K, Lynch J, Araya R. Country- and individual-level socioeconomic determinants of depression: Multilevel cross-national comparison. $\mathrm{Br}$ J Psychiatry. 2013;202:195-203.

128. Arnone D, Mclntosh AM, Ebmeier KP, Munafò MR, Anderson IM. Magnetic resonance imaging studies in unipolar depression: Systematic review and metaregression analyses. Eur Neuropsychopharmacol. 2012;22:1-16.

129. Sacher J, Neumann J, Fünfstück T, Soliman A, Villringer A, Schroeter ML. Mapping the depressed brain: A meta-analysis of structural and functional alterations in major depressive disorder. J Affect Disord. 2012;140:142-8.

130. Schmaal L, Veltman DJ, van Erp TGM, Sämann PG, Frodl T, Jahanshad N, et al. Subcortical brain alterations in major depressive disorder: Findings from the ENIGMA Major Depressive Disorder working group. Mol Psychiatry. 2016;21:806-12.

131. Wise T, Radua J, Via E, Cardoner N, Abe O, Adams TM, et al. Common and distinct patterns of grey-matter volume alteration in major depression and bipolar disorder: Evidence from voxel-based meta-analysis. Mol Psychiatry. 2016;22:1455-63.

132. Koolschijn PCMP, van Haren NEM, Lensvelt-Mulders GJLM, Hulshoff Pol HE, Kahn RS. Brain volume abnormalities in major depressive disorder: A meta-analysis of magnetic resonance imaging studies. Hum Brain Mapp. 2009;30:3719-35.

133. Repple J, Meinert S, Grotegerd D, Kugel H, Redlich R, Dohm K, et al. A voxelbased diffusion tensor imaging study in unipolar and bipolar depression. Bipolar Disord. 2017:19:23-31.

134. Sexton CE, Mackay CE, Ebmeier KP. A systematic review of diffusion tensor imaging studies in affective disorders. Biol Psychiatry. 2009;66:814-23.

135. Yamada S, Takahashi S, Ukai S, Tsuji T, Iwatani J, Tsuda K, et al. Microstructural abnormalities in anterior callosal fibers and their relationship with cognitive function in major depressive disorder and bipolar disorder: A tract-specific analysis study. J Affect Disord. 2015;174:542-8.

136. Whittle S, Lichter R, Dennison M, Vijayakumar N, Schwartz O, Byrne ML, et al. Structural brain development and depression onset during adolescence: $\mathrm{A}$ prospective longitudinal study. Am J Psychiatry. 2014;171:564-71.

137. McGrath J, Saha S, Chant D, Welham J. Schizophrenia: A concise overview of incidence, prevalence, and mortality. Epidemiol Rev. 2008;30:67-76.

138. Saha S, Chant D, Welham J, McGrath J. A systematic review of the prevalence of schizophrenia. PLoS Med. 2005;2:0413-33.

139. Häfner H. Schizophrenia: Do men and women suffer from the same disease? Rev Psiquiatr Clin. 2002;29:267-92.

140. Fraguas D, Díaz-Caneja CM, Pina-Camacho L, Janssen J, Arango C. Progressive brain changes in children and adolescents with early-onset psychosis: A metaanalysis of longitudinal MRI studies. Schizophr Res. 2016;173:132-9.
141. Corcoran CM, Kimhy D, Parrilla-Escobar MA, Cressman VL, Stanford AD, Thompson J, et al. The relationship of social function to depressive and negative symptoms in individuals at clinical high risk for psychosis. Psychol Med. 2011;41:251-61.

142. Amminger GP, Leicester S, Yung AR, Phillips LJ, Berger GE, Francey SM, et al. Early-onset of symptoms predicts conversion to non-affective psychosis in ultrahigh risk individuals. Schizophr Res. 2006;84:67-76.

143. Barajas A, Ochoa S, Obiols JE, Lalucat-Jo L. Gender differences in individuals at high-risk of psychosis: A comprehensive literature review. Sci World J. 2015;2015:1-13.

144. Usall J, Ochoa S, Araya S, Márquez M. Gender differences and outcome in schizophrenia: A 2-year follow-up study in a large community sample. Eur Psychiatry. 2003;18:282-4.

145. Hunt IM, Kapur N, Windfuhr K, Robinson J, Bickley H, Flynn S, et al. Suicide in schizophrenia: Findings from a national clinical survey. J Psychiatr Pract. 2006;12:139-47.

146. Okada N, Fukunaga M, Yamashita F, Koshiyama D, Yamamori H, Ohi K, et al. Abnormal asymmetries in subcortical brain volume in schizophrenia. Mol Psychiatry. 2016;21:1460-6.

147. Satterthwaite TD, Wolf DH, Calkins ME, Vandekar SN, Erus G, Ruparel K, et al. Structural brain abnormalities in youth with psychosis spectrum symptoms. JAMA Psychiatry. 2016b;73:515-24.

148. Van Erp TGM, Hibar DP, Rasmussen JM, Glahn DC, Pearlson GD, Andreassen OA, et al. Subcortical brain volume abnormalities in 2028 individuals with schizophrenia and 2540 healthy controls via the ENIGMA consortium. Mol Psychiatry. 2016:21:547-53.

149. Haijma SV, Van Haren N, Cahn W, Koolschijn PCMP, Hulshoff Pol HE, Kahn RS. Brain volumes in schizophrenia: A meta-analysis in over 18000 subjects. Schizophr Bull. 2013;39:1129-38.

150. Bora E, Fornito A, Radua J, Walterfang M, Seal M, Wood SJ, et al. Neuroanatomical abnormalities in schizophrenia: A multimodal voxelwise meta-analysis and meta-regression analysis. Schizophr Res. 2011;127:46-57.

151. Honea R, Crow TJ, Passingham D, Mackay CE. Regional deficits in brain volume in schizophrenia: A meta-analysis of voxel-based morphometry studies. Am J Psychiatry. 2005;162:2233-45.

152. Rozycki M, Satterthwaite TD, Koutsouleris N, Erus G, Doshi J, Wolf DH, et al. Multisite machine learning analysis provides a robust structural imaging signature of schizophrenia detectable across diverse patient populations and within individuals. Schizophr Bull. (2017).

153. Glahn DC, Laird AR, Ellison-Wright I, Thelen SM, Robinson JL, Lancaster JL, et al. Meta-analysis of gray matter anomalies in schizophrenia: Application of anatomic likelihood estimation and network analysis. Biol Psychiatry. 2008;64:774-81.

154. Gupta CN, Calhoun VD, Rachakonda S, Chen J, Patel V, Liu J, et al. Patterns of gray matter abnormalities in schizophrenia based on an international megaanalysis. Schizophr Bull. 2015:41:1133-42.

155. Shahab S, Stefanik L, Foussias G, Lai MC, Anderson KK, Voineskos AN. Sex and diffusion tensor imaging of white matter in schizophrenia: A systematic review plus meta-analysis of the corpus callosum. Schizophr Bull. 2018:44:203-21.

156. Adriano F, Caltagirone C, Spalletta G. Hippocampal volume reduction in firstepisode and chronic schizophrenia: A review and meta-analysis. Neuroscientist. 2012;18:180-200.

157. Bois C, Levita L, Ripp I, Owens DCG, Johnstone EC, Whalley HC, et al. Hippocampal, amygdala and nucleus accumbens volume in first-episode schizophrenia patients and individuals at high familial risk: A cross-sectional comparison. Schizophr Res. 2015;165:45-51.

158. Cannon TD. How schizophrenia develops: Cognitive and brain mechanisms underlying onset of psychosis. Trends Cogn Sci. 2015;19:744-56.

159. Chan RCK, Di X, McAlonan GM, Gong QY. Brain anatomical abnormalities in high-risk individuals, first-episode, and chronic schizophrenia: An activation likelihood estimation meta-analysis of illness progression. Schizophr Bull. 2011;37:177-88.

160. Weisinger B, Greenstein D, Mattai A, Clasen L, Lalonde F, Feldman S, et al. Lack of gender influence on cortical and subcortical gray matter development in childhood-onset schizophrenia. Schizophr Bull. 2013;39:52-58.

161. Bartels M, Cacioppo JT, van Beijsterveldt TCEM, Boomsma DI. Exploring the association between well-being and psychopathology in adolescents. Behav Genet. 2013;43:177-90.

162. Tung I, Li JJ, Meza Jl, Jezior KL, Kianmahd JSV, Hentschel PG, et al. Patterns of comorbidity among girls with ADHD: A meta-analysis. Pediatrics. 2016;138:1-13.

163. Taylor MJ, Lichtenstein P, Larsson H, Anckarsäter H, Greven CU, Ronald A. Is there a female protective effect against attention-deficit/hyperactivity disorder? Evidence from two representative twin samples. J Am Acad Child Adolesc Psychiatry. 2016;55:504-512.e2. 
164. Nakao T, Radua J, Rubia K, Mataix-Cols D. Gray matter volume abnormalities in ADHD: Voxel-based meta-analysis exploring the effects of age and stimulant medication. Am J Psychiatry. 2011;168:1154-63.

165. Valera EM, Faraone SV, Murray KE, Seidman LJ. Meta-analysis of structural imaging findings in attention-deficit/hyperactivity disorder. Biol Psychiatry. 2007;61:1361-9.

166. Castellanos XF, Lee PP, Sharp W, Jeffries NO, Greenstein DK, Clasen LS, et al. Developmental trajectories of brain volume abnormalities in children and adolescents with attention-deficit/hyperactivity disorder. JAMA. 2002;288:1740-8.

167. de Zeeuw P, Schnack HG, van Belle J, Weusten J, van Dijk S, Langen $M$, et al. Differential brain development with low and high IQ in attention-deficit/ hyperactivity disorder. PLoS One. 2012;7:1-11.

168. Durston S, Hulshoff Pol HE, Schnack HG, Buitelaar JK, Steenhuis MP, Minderaa $\mathrm{RB}$, et al. Magnetic resonance imaging of boys with attention-deficit/hyperactivity disorder and their unaffected siblings. J Am Acad Child Adolesc Psychiatry. 2004;43:332-40.

169. Makris N, Biederman J, Valera EM, Bush G, Kaiser J, Kennedy DN, et al. Cortical thinning of the attention and executive function networks in adults with attention-deficit/hyperactivity disorder. Cereb Cortex. 2007; 17:1364-75.

170. Shaw P, Eckstrand K, Sharp W, Blumenthal J, Lerch JP, Greenstein D, et al. Attention-deficit/hyperactivity disorder is characterized by a delay in cortical maturation. Proc Natl Acad Sci. 2007;104:19649-54.

171. Shaw P, Malek M, Watson B, Sharp W, Evans A, Greenstein D. Development of cortical surface area and gyrification in attention-deficit/hyperactivity disorder. Biol Psychiatry. 2012;72:191-7.

172. Shaw $P$, Malek M, Watson B, Greenstein D, de Rossi P, Sharp W. Trajectories of cerebral cortical development in childhood and adolescence and adult attention-deficit/hyperactivity disorder. Biol Psychiatry. 2013;74:599-606.

173. van Ewijk H, Heslenfeld DJ, Zwiers MP, Buitelaar JK, Oosterlaan J. Diffusion tensor imaging in attention deficit/hyperactivity disorder: A systematic review and meta-analysis. Neurosci Biobehav Rev. 2012;36:1093-106.

174. Mahone EM, Ranta ME, Crocetti D, O'Brien J, Kaufmann WE, Denckla MB, et al. Comprehensive examination of frontal regions in boys and girls with attentiondeficit/hyperactivity disorder. J Int Neuropsychol Soc. 2011;17:1047-57.

175. Dirlikov B, Shiels Rosch K, Crocetti D, Denckla MB, Mahone EM, Mostofsky SH. Distinct frontal lobe morphology in girls and boys with ADHD. Neuroimage Clin. 2015;7:222-9.

176. Nooner KB, Colcombe SJ, Tobe RH, Mennes M, Benedict MM, Moreno AL, et al. The NKI-Rockland sample: A model for accelerating the pace of discovery science in psychiatry. Front Neurosci. 2012;6:1-11.

177. Satterthwaite TD, Connolly JJ, Ruparel K, Calkins ME, Jackson C, Elliott MA, et al. The Philadelphia Neurodevelopmental Cohort: A publicly available resource for the study of normal and abnormal brain development in youth. Neuroimage. 2016a;124:1115-9.

178. Jernigan TL, Brown TT, Hagler DJ, Akshoomoff $N$, Bartsch $H$, Newman $E$, et al. The Pediatric Imaging, Neurocognition, and Genetics (PING) data repository. Neuroimage. 2016;124:1149-54.

179. Ances B, Bookheimer S, Buckner R, Salat D, Smith S, Terpstra M, et al.: Human Connectome Project-Lifespan studies. Date accessed: March 1 2018. https:// www.humanconnectome.org/lifespan-studies

180. Alexander LM, Escalera J, Ai L, Andreotti C, Febre K, Mangone A, et al. Data descriptor: An open resource for transdiagnostic research in pediatric mental health and learning disorders. Sci Data. 2017;4:1-26.

181. National Institutes of Health: Adolescent Brain Cognitive Development Study (ABCD). Date accessed: March 1 2018. https://addictionresearch.nih.gov/abcdstudy

182. Belsky J. Experiencing the lifespan. New York, NY: Worth Publishers; 2007.

183. Piekarski DJ, Johnson CM, Boivin JR, Thomas AW, Lin WC, Delevich K, et al. Does puberty mark a transition in sensitive periods for plasticity in the associative neocortex? Brain Res. 2017;1654:123-44.

184. Herting MM, Sowell ER. Puberty and structural brain development in humans. Front Neuroendocrinol. 2017:44:122-37.

185. Mendle J. Why puberty matters for psychopathology. Child Dev Perspect. 2014;8:218-22.

186. Chumlea WC, Schubert CM, Roche AF, Kulin HE, Lee PA, Himes JH, et al. Age at menarche and racial comparisons in US girls. Pediatrics. 2003;111:110-3.

187. Mills KL, Goddings AL, Herting MM, Meuwese R, Blakemore SJ, Crone EA, et al. Structural brain development between childhood and adulthood: Convergence across four longitudinal samples. Neuroimage. 2016;141:273-81.

188. Juraska JM, Willing J. Pubertal onset as a critical transition for neural development and cognition. Brain Res. 2017;1654:87-94.

189. Blanco $C$, Wall M, Lindquist $M$, Rodriguez-Fernandez J, Franco $S$, Wang $S$, et al Generalizability of neuroimaging studies in 5 common psychiatric disorders based on the National Epidemiological Survey on Alchol and Related Conditions (NESARC). J Clin Psychiatry. 2016;77:1618-25.

190. Mankiw C, Park MTM, Reardon PK, Fish AM, Clasen LS, Greenstein D, et al. Allometric analysis detects brain size-independent effects of sex and sex chromosome complement on human cerebellar organization. J Neurosci. 2017;37:5221-31. Proposed a novel method for accounting for global sex differences in brain size using allometric norms and showed such scaling could be used to reveal that cerebellar subcomponents are sensitive to sex and sex chromosome dose.

191. Cahill L. Why sex matters for neuroscience. Nat Rev Neurosci. 2006;7:477-84.

192. Cahill L. An issue whose time has come. J Neurosci Res. 2017;95:12-13.

193. Miller VM, Rocca WA, Faubion SS. Sex differences research, precisionmedicine, and the future of women's health. J Women's Heal. 2015;24:969-71. 